\title{
Patterns and determinants of antenatal care utilization: analysis of national survey data in seven countdown countries
}

\author{
Ghada Saad-Haddad ${ }^{1}$, \\ Jocelyn DeJong ${ }^{1}$, \\ Nancy Terreri ${ }^{2}$, María Clara \\ Restrepo-Méndez ${ }^{3}$, \\ Jamie Perin ${ }^{4}$, Lara Vaz ${ }^{5}$, \\ Holly Newby ${ }^{6}$, \\ Agbessi Amouzou ${ }^{6}$, \\ Aluísio JD Barros ${ }^{3}$, \\ Jennifer Bryce ${ }^{7}$ \\ ${ }^{1}$ Faculty of Health Sciences, American \\ University of Beirut, Beirut, Lebanon \\ ${ }^{2}$ Independent consultant \\ ${ }^{3}$ Federal University of Pelotas, Pelotas, \\ Brazil \\ ${ }^{4}$ Institute for International Programs, \\ Johns Hopkins Bloomberg School of \\ Public Health, Baltimore, MD, USA \\ ${ }^{5}$ Save the Children, Washington D.C., \\ USA \\ ${ }^{6}$ Division of Data, Research and Policy, \\ United Nations Children's Fund, New \\ York City, NY, USA \\ ${ }^{7}$ Institute for International Programs, \\ Johns Hopkins Bloomberg School of \\ Public Health, Baltimore, MD, USA
}

Background Antenatal care (ANC) is critical for improving maternal and newborn health. WHO recommends that pregnant women complete at least four ANC visits. Countdown and other global monitoring efforts track the proportions of women who receive one or more visits by a skilled provider ( $\mathrm{ANCl}+$ ) and four or more visits by any provider (ANC4+). This study investigates patterns of drop-off in use between $\mathrm{ANC1}+$ and $\mathrm{ANC4}+$, and explores inequalities in women's use of ANC services. It also identifies determinants of utilization and describes countries' ANCrelated policies, and programs.

Methods We performed secondary analyses using Demographic Health Survey (DHS) data from seven Countdown countries: Bangladesh, Cambodia, Cameroon, Nepal, Peru, Senegal and Uganda. The descriptive analysis illustrates country variations in the frequency of visits by provider type, content, and by household wealth, women's education and type of residence. We conducted a multivariable analysis using a conceptual framework to identify determinants of ANC utilization. We collected contextual information from countries through a standard questionnaire completed by country-based informants.

Results Each country had a unique pattern of ANC utilization in terms of coverage, inequality and the extent to which predictors affected the frequency of visits. Nevertheless, common patterns arise. Women having four or more visits usually saw a skilled provider at least once, and received more evidence-based content interventions than women reporting fewer than four visits. A considerable proportion of women reporting four or more visits did not report receiving the essential interventions. Large disparities exist in ANC use by household wealth, women's education and residence area; and are wider for a larger number of visits. The multivariable analyses of two models in each country showed that determinants had different effects on the dependent variable in each model. Overall, strong predictors of ANC initiation and having a higher frequency (4+) of visits were woman's education and household wealth. Gestational age at first visit, birth rank and preceding birth interval were generally negatively associated with initiating visits and with having four or more visits. Information on country policies and programs were somewhat informative in understanding the utilization patterns across the countries, although timing of adoption and actual implementation make direct linkages impossible to verify.

Conclusion Secondary analyses provided a more detailed picture of ANC utilization patterns in the seven countries. While coverage levels differ by country and sub-groups, all countries can benefit from specific in-country assessments to properly identify the underserved women and the reasons behind low coverage and missed interventions. Overall, emphasis needs to be put on assessing the quality of care offered and identifying women's perception to the care as well as the barriers hindering utilization. Country policies and programs need to be reviewed, evaluated and/or implemented properly to ensure that women receive the recommended number of ANC visits with appropriate content, especially, poor and less educated women residing in rural areas. 
Antenatal care (ANC), defined as the care provided to a woman during her pregnancy, is an essential component of reproductive health care. ANC can serve as a platform for the delivery of highly-effective health interventions that can reduce preventable maternal and newborn deaths $[1,2]$. ANC services offer pregnant women an entry point to the health care system, providing appropriate screening, intervention and treatment throughout pregnancy, and encouraging women to seek a skilled birth attendant for their delivery [3]. Furthermore, using ANC allows women to receive information about improving maternal health through proper nutrition and self-care during pregnancy; and throughout the postpartum period, such as the benefits of exclusive breastfeeding and counseling on family planning methods [4].

The current World Health Organization (WHO) recommendation is that each woman receives a minimum of four goaloriented or focused ANC visits for low-risk deliveries, to be supervised or attended by a skilled ANC attendant [4]. The timing of the first visit should be before 16 weeks of pregnancy, the second visit should be between 24 and 26 weeks, the third visit between 30 and 32 weeks, and the fourth visit between 36 and 38 weeks [5]. WHO defines a thorough set of essential elements for each visit (Box 1).

Coverage of ANC has been used globally as one of the indicators to track progress towards Target 5.B (achieving universal access to reproductive health by 2015) under Millennium Development Goal 5 (MDG 5) to improve maternal health [12]. The official ANC indicators for global tracking are: (1) the proportion of women with a recent live birth who report at least one ANC visit with skilled health personnel (ANC 1+); and (2) the proportion of women with a recent live birth who report at least four ANC visits with any provider (ANC 4+) [12]. The Countdown to 2015 for Maternal, Newborn and Child Survival, a global movement that tracks coverage for evidence-based interventions in 75 countries that account for more than $95 \%$ of maternal and child deaths [13], also reports on the ANC 1+ and ANC 4+ indicators.

There have been numerous studies of the determinants of ANC use in low- and middle-income countries. Fewer studies have examined the determinants of use by frequency of antenatal care visits, comparatively, and through inferential analyses [14-21]. There have also been several analyses of equity in utilization of ANC services. Relevant articles stratify utilization by urban/rural place of residence [16,22-24], and less frequently, by mother's education [15,25], wealth [15,26], income [25], and ethnicity [25]. However, little is known about the frequency of ANC visits in general, especially as a comparative presentation across countries. No previous study, to our knowledge, has examined utilization in terms of what the globally measured
Box 1. The evolution of World Health Organization guidelines for antenatal care visits

The concept of antenatal care originated in Europe in the early decades of the $20^{\text {th }}$ century. It is believed that the ANC model and the recommendations set at that time formed the foundation for ANC programs worldwide. The model indicated that visits should begin around 16 weeks of gestation, followed by visits at 24 and 28 weeks, then fortnightly visits until 36 weeks, and finally, weekly visits until delivery [6].

This 'Western model' was implemented for developing countries without taking into consideration contextual factors, which are especially important in low-resource settings [7]. WHO therefore developed a new model of ANC, consisting of a reduced number of visits and specifying the evidencebased interventions to be provided at each visit, including: assessment of the pregnant woman; screening for pre-eclampsia, anemia, syphilis, and HIV; provision of preventive measures such as checking of iron and folate dosage, tetanus toxoid immunization, anti-malarial precautions, and advice on labor or danger signs; advise on proper self-care, nutrition, and substance abuse; and counseling on the importance of family planning [5]. These recommendations are referred to as "focused" or "goal-oriented" ANC. Clinical evidence at the time the recommendations were released indicated that health outcomes were similar for women who received the four focused visits and women who received standard ANC with more visits $[7,8]$.

Dowswell and colleagues [6] in an updated Cochrane systematic review using new methods of assessment, showed a statistically significant increase in perinatal mortality in low- and middle-income settings among women who received focused ANC compared to women who received standard ANC. In a 2011 statement, WHO acknowledged this and planned to provide updated guidelines for ANC based on their findings to be generated from additional secondary analyses [9]. The results of a secondary analysis looking at the WHO ANC trial were published in 2013, again showing a substantial increase in perinatal mortality among women receiving the focused ANC compared to those receiving the standard package, especially between 32 and 36 weeks of gestation. However, the findings also showed high levels of heterogeneity between the populations in the trials, and suggested that differences in perinatal mortality between the control and intervention groups could be attributed to different settings, populations or even quality of care received [10]. The WHO is re-evaluating its ANC guidelines, an exercise which is expected to be completed by the end of 2015 [11].

ANC indicators might be missing with respect to associations between women's characteristics and their patterns of visits. Moreover, qualitative studies, or studies that use both qualitative and quantitative methods, are fewer in number [27]. These studies focus on contextual aspects such as the presence of health care workers in the community, availability of affordable care, household characteristics and per- 
ceived distance from the health care facility, waiting time at the facility [27], women's perceptions about ANC, and their experiences, attitudes, beliefs and perceived need for services $[27,28]$.

For this paper, we purposely selected a limited number of Countdown countries to examine and understand the underlying patterns of ANC utilization that are not revealed when relying solely on the globally measured ANC indicators. We identify whether a significant drop-off in utilization occurs after a certain number of visits. We also describe the number of ANC visits by the type of provider, and the content received overall during ANC. We examine the coverage of ANC by three measures of inequality. Finally, we use several environmental, population and individual characteristics to analyze utilization patterns in the selected countries. In addition, contextual information on policy and program structure was collected from the selected countries for the purpose of improving understanding of ANC coverage levels and drop off.

\section{DATA AND METHODOLOGY}

\section{Data}

The selection of countries was based on several criteria with the desire to have six to seven Countdown countries from different world regions, each with a Demographic Health Survey (DHS) in 2010 or later. We chose countries with extreme coverage levels (high or low) of ANC 4+, ANC 1+ and skilled birth attendance. We also selected a couple of countries identified as priority countries for eliminating motherto-child transmission of HIV (list of the Countdown countries in Table S1 in Online Supplementary Document). The seven selected Countdown countries are Bangladesh, Cambodia, Cameroon, Nepal, Peru, Senegal and Uganda.

Data for our analyses were obtained from nationally-representative household surveys conducted under the DHS program [29]. Information on the number of ANC visits for the most recent live birth in the five years preceding the survey for each woman in the sample was found in the women's individual questionnaire. Women who responded "don't know" or had a missing response were excluded from the analysis. Missing variables found in responses to the other variables we chose for our descriptive and inferential statistics were handled similarly and observations were dropped from the analysis (proportions of missing varied between variables in each country and across countries but never exceed a proportion of $0.7 \%$ of the total sample size per country). The following DHS surveys were used for the analyses presented in this work: Bangladesh 2011, Cambodia 2010, Cameroon 2011, Nepal 2011, Peru 2012, Senegal 2010, Uganda 2011.

\section{Methodology}

The bulk of this study consisted of a thorough descriptive analysis to unpack the ANC indicators. We analyzed ANC visit frequency by type of provider reported and by content interventions received. In each survey, women were asked to list the providers they saw during any ANC visit. We categorized women who reported having ANC into those who saw a skilled provider for at least one visit and those who saw unskilled providers only (the list of providers in Table S2 in Online Supplementary Document). We selected a limited number of evidence-based content interventions that should be routinely administered during ANC visits and data usually available through DHS: blood sample taken, blood pressure taken, urine sample taken and being told about pregnancy problems. In Bangladesh, only being told about pregnancy problems was available, as the other questions were not asked. We examined differences in content received among women who saw a skilled provider vs those who saw only an unskilled provider, and the pattern of content received by wealth quintile. We charted the frequency of visits by gestational age at first ANC visit (by trimester). In Bangladesh, no data were collected on this variable. We also investigated inequalities in utilization of ANC visits by three dimensions of inequality, specifically, women's education (none, primary, secondary, and higher), household wealth quintile (five wealth quintiles from poorest to richest as defined by DHS) and the area of residence (rural or urban). We described the differences in proportions of women's reported frequency of visits by each of the three dimensions.

To identify the determinants that affected women's choices in initiating ANC and the seeking patterns among women who reported receiving ANC, we adopted Anderson's Behavioral Model for Healthcare Use [30], specifically four components of the model and a selection of 15 determinants (Figure 1). Anderson's Behavioral Model has been used extensively to understand utilization in different health care settings [32]. Numerous studies have made use of this conceptual model to study the determinants of antenatal care utilization $[17,19,32,33]$. We assessed the factors that influence the frequency of ANC visits for two comparisons: those reporting no visits vs those reporting one or more visits; and those reporting one to three visits vs those reporting four or more visits. After examining the bivariate relationships between each determinant and the dependent outcomes, we performed multivariable logistic regression analyses. Using the strategy of hierarchical entry of variables [34], we first included the external environment factors into the models to assess their association with the outcome variable. Using backward elimination we exclude factors not significant $(P<0.05)$ at the level being entered, one at a time, starting with the variable with the 
ENVIRONMENT

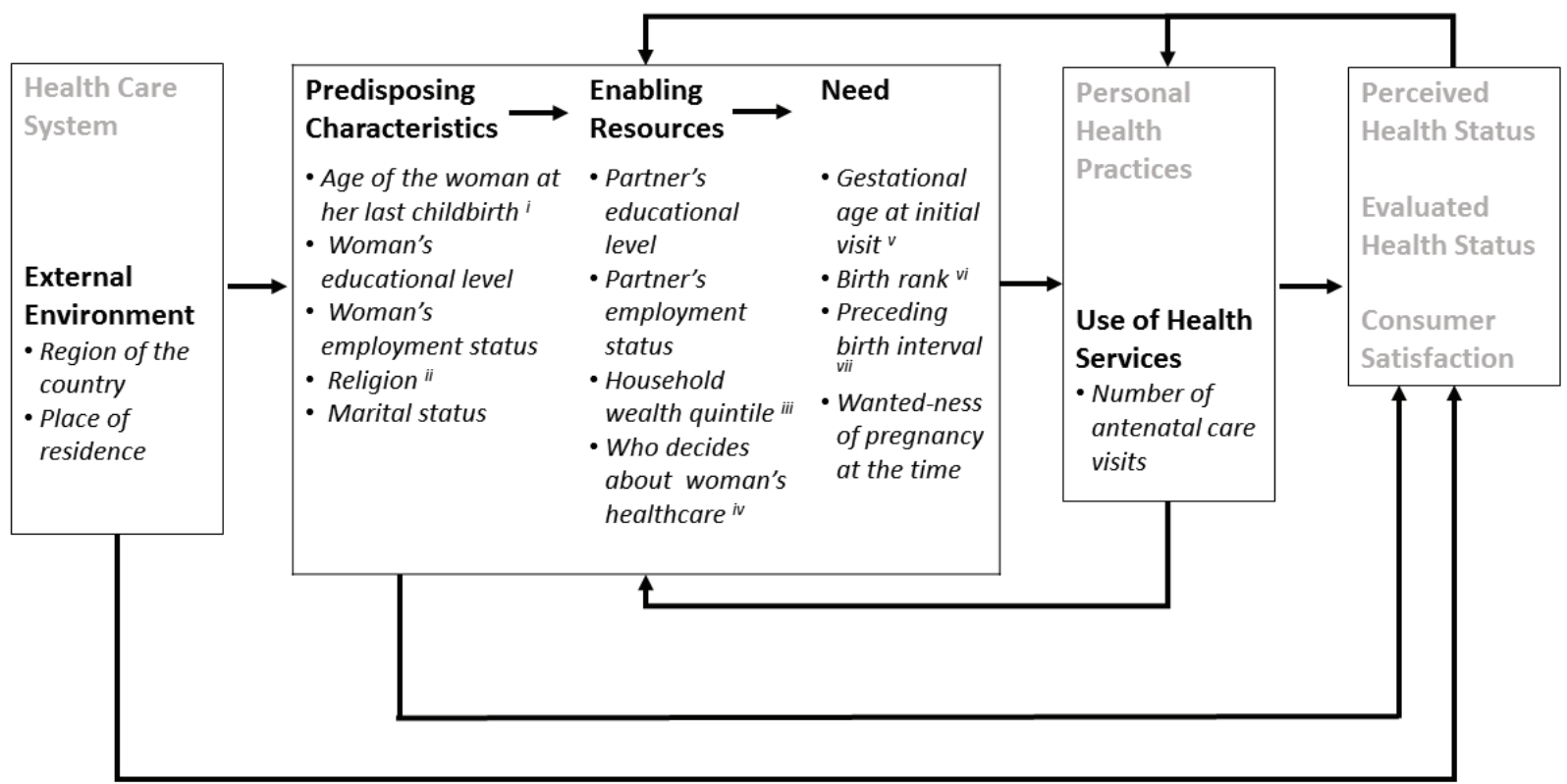

Figure 1. The conceptual framework based on Anderson's Behavioral Model of Healthcare Use and the corresponding determinants used in our secondary analysis [31]. Source: Anderson 1995 [31]. ${ }^{i}$ Age at woman's most recent birth was calculated by subtracting

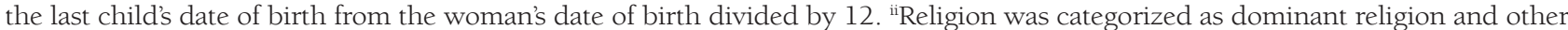
religions. iii Household wealth quintile is made up of five wealth quintiles from poorest to richest as constructed by DHS where each quintile represents $20 \%$ of the households in the study sample. ${ }^{i}$ The variable 'who decides about woman's health care' is categorized as: woman alone, woman \& partner, partner alone, someone else. ${ }^{v}$ Gestational age at first ANC visit was grouped into trimesters. ${ }^{v i}$ Birth rank was categorized as: $1^{\text {st }}-2^{\text {nd }}$ birth, $3^{\text {rd }}-4^{\text {th }}$ birth, $5^{\text {th }}$ birth or more. viiPreceding birth interval was grouped into: first birth (no interval), less than 2 years interval, 2-3 years interval, more than 3 years interval.

highest $P$-value. We re-ran the models until all the variables at the level being entered were significant. After looking at the model with environmental variables only, we added the predisposing characteristics to the models followed by a reapplication of the backward elimination procedure. The enabling factors and the need factors were then added to the models using similar procedures.

We analyzed the data with Stata (StataCorp. 2013. Stata Statistical Software: Release 13; College Station, TX: StataCorp LP) using the 'svy' prefix to take into account the complex sample design, including sampling weights and clustering.

\section{Collection of information on ANC-related national policies and programs}

We collected information on policy and programming for ANC in each of the seven countries by identifying a government official, researcher and/or non-governmental organization (NGO) staff knowledgeable about current and past ANC policy and programs and willing to assist. Each key informant was encouraged to contact additional resource persons as necessary and to provide the research team with copies of relevant documents. We developed and provided informants with a self-administered standard. Topics covered in the questionnaire included information on country policies and guidelines, with details on recommended timing, number and content of ANC visits. Additional information requested included the locations of ANC service provision in each country, the types of providers, incentives for women to seek care, user fees, incentives for providers, communication or social marketing around ANC, and how the ANC service is organized. Most questions were open-ended, and a final question asked for any additional comments from the informant on how uptake of ANC services might be improved. To assist the informant in filling out the questionnaire and for verification purposes, each country questionnaire included pre-completed descriptive information from the latest country DHS or other publication, when available

One member of the research team reviewed global policies relevant to ANC, compiled results from the country questionnaires, reviewed documents provided by key informants and others found through online searches. Followup with key informants was made to provide missing information or to resolve discrepancies. Descriptive summaries and tables were completed for each country along 


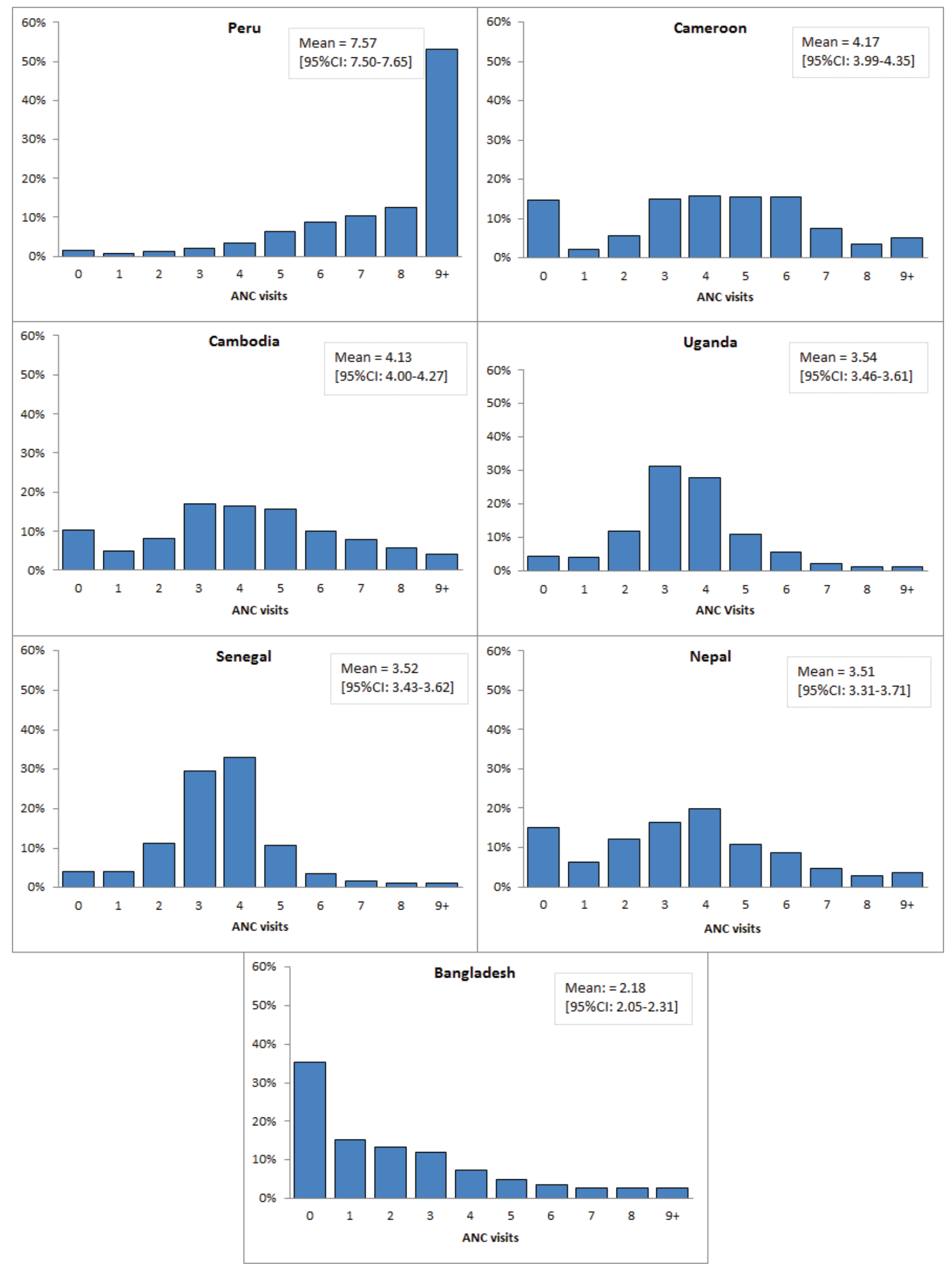

Figure 2. Percentage of women who had a live birth in the five years preceding the DHS surveys reporting zero to more than nine ANC visits for their most recent live birth, and mean of ANC visits among all these women ( $95 \%$ confidence intervals), in seven Countdown countries. 
with an overall summary of findings. Results were shared with the research team and used in analyzing the country results.

\section{RESULTS}

The seven countries we selected for this secondary analysis are Bangladesh, Cambodia, Cameroon, Nepal, Peru, Senegal and Uganda. The un-weighted sample sizes of women aged 15-49 years in each country were: 7319 (ever-married women only) in Bangladesh; 6421 women in Cambodia; 7576 women in Cameroon; 4079 women in Nepal; 7991 women in Peru; 8008 women in Senegal and 4818 women in Uganda.

\section{Descriptive analysis}

Table 1 describes the proportions of women reporting one or more and four or more ANC visits with a skilled provider or any provider. With the exception of Bangladesh and Nepal, 85-96\% of the women reported at least one ANC visit with a skilled provider. In Bangladesh, around one-third of the women reported not receiving any ANC. The proportion of women who reported four or more visits ranged from $48 \%$ to $63 \%$ in five of the seven countries. Bangladesh was at the low end, with 24\% and Peru stood out with $94 \%$. Despite the fact that the globally measured ANC indicators are not fully comparable, because the ANC $1+$ indicator refers to visits with a skilled provider and ANC $4+$ refers to visits with any provider, it is important to note that in five out of the seven countries, over $90 \%$ of the women who reported receiving four or more visits with any provider also reported receiving at least one visit with a skilled provider (Table $\mathbf{1}$ ).

The distribution of number of ANC visits varies from country to country, as shown in Figure 2. Peru has the highest mean (7.6); Cameroon and Cambodia have a mean of just over four reported ANC visits. The distributions in Bangla- desh and Peru represent two extremes, with a right skewed distribution in Bangladesh (35\% of women with no visits) and a left skewed distribution in Peru (nearly no women reporting zero ANC visits). Most women who reported no ANC visits reside in rural areas, are in the two poorest quintiles of their national populations, and have less than a primary school education (data not shown).

We present the cumulative distribution of ANC visits by provider type and the relative decline in proportions of women across the visits in Figure 3. In Bangladesh, Cambodia, Cameroon and Peru, the proportions of women who reported receiving ANC appears to gradually decrease as the number of visits increases. In Senegal and Uganda, there seems to be a pronounced drop off between three and four or more visits; in Nepal this noticeable drop off occurs between four and five visits. Similar to the results in Table $\mathbf{1}$, most women reported receiving care from a skilled provider during one or more ANC visits. The relative decline in the proportion of women who reported receiving care from unskilled providers decreased faster than the relative decline of the proportion of women who reported receiving care from skilled providers, as the reported number of visits increased.

We show the percentage of women receiving selected content interventions during any ANC visit among women reporting one to three or four or more visits in Figure 4. Women who reported four or more visits reported receiving at least one content intervention more than women reporting one to three visits, even though the increase in proportions varied across countries and among interventions; this pattern is also visible after stratifying the percentage of women receiving content by type of provider reported (Table S3 in Online Supplementary Document) However, a considerable proportion of women who reported the recommended four or more ANC visits did not receive any of the essential interventions at least once. Women who reported receiving ANC services and seeing a skilled provider at least once, seemed to report receiving more content

Table 1. Percentage of women who had a live birth in the five years preceding the DHS surveys who reported one ANC visit with a skilled provider and four or more visits with any provider or skilled provider for their most recent live birth, in seven Countdown countries

\begin{tabular}{|c|c|c|c|c|c|}
\hline & $\begin{array}{l}\text { OME OR MORE ANC } \\
\text { VISIIS WITH ANY } \\
\text { PROVIDER }(\%)\end{array}$ & $\begin{array}{l}\text { ANC } 1+\text { (พITH A } \\
\text { SKILED PROVIDER) (\%) }\end{array}$ & $\begin{array}{l}\text { ANC } 4+\text { (WITH } \\
\text { ANY PROVIDER) (\%) }\end{array}$ & $\begin{array}{l}\text { FoUR OR MORE ANC VISITS } \\
\text { WITH A SKILLED PROVIDER* }(\%)\end{array}$ & $\begin{array}{l}\text { WOMEN REPORTING ANC } 4+\text { WITH ANY PROVIDER } \\
\text { AND PRESENT AS A SUBSET AMONG WOMEN REPORTING } \\
\text { ANC } 1+\text { WITH A SKILLED PROVIDER (\%) }\end{array}$ \\
\hline Bangladesh 2011 & 64.6 & 51.7 & 23.9 & 19.9 & 83.4 \\
\hline Cambodia 2010 & 89.6 & 89.1 & 59.6 & 59.4 & 99.7 \\
\hline Cameroon 2011 & 85.4 & 84.9 & 62.9 & 62.7 & 99.7 \\
\hline Nepal 2011 & 84.9 & 58.2 & 50.1 & 40.0 & 79.8 \\
\hline Peru 2012 & 98.4 & 96.0 & 94.4 & 92.2 & 97.6 \\
\hline Senegal 2010 & 95.8 & 93.2 & 51.2 & 50.2 & 98.1 \\
\hline Uganda 2011 & 95.7 & 94.8 & 48.5 & 48.1 & 99.3 \\
\hline
\end{tabular}

DHS - Demographic Health survey, ANC - antenatal care

*At least one visit of the four or more visits is with a skilled provider. 
Legend:

Skilled provider seen at least once

Unskilled provider

3. Relative decline in coverage of visits

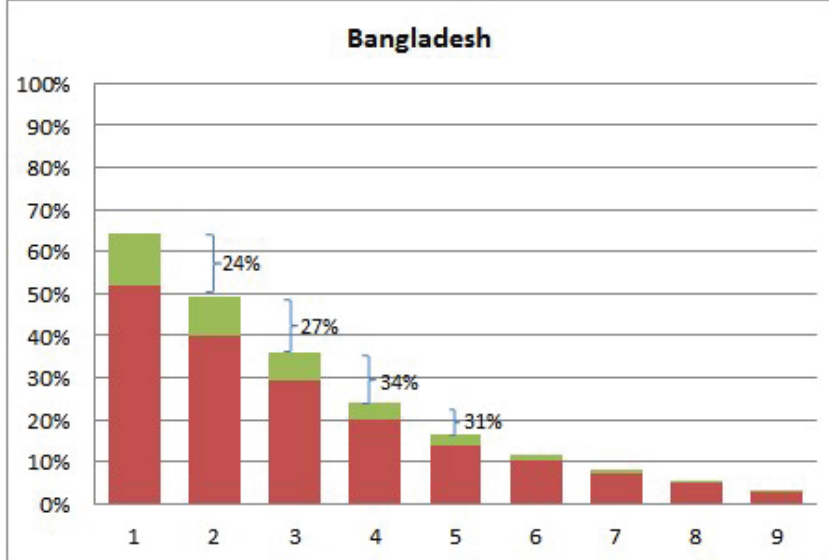

Cameroon
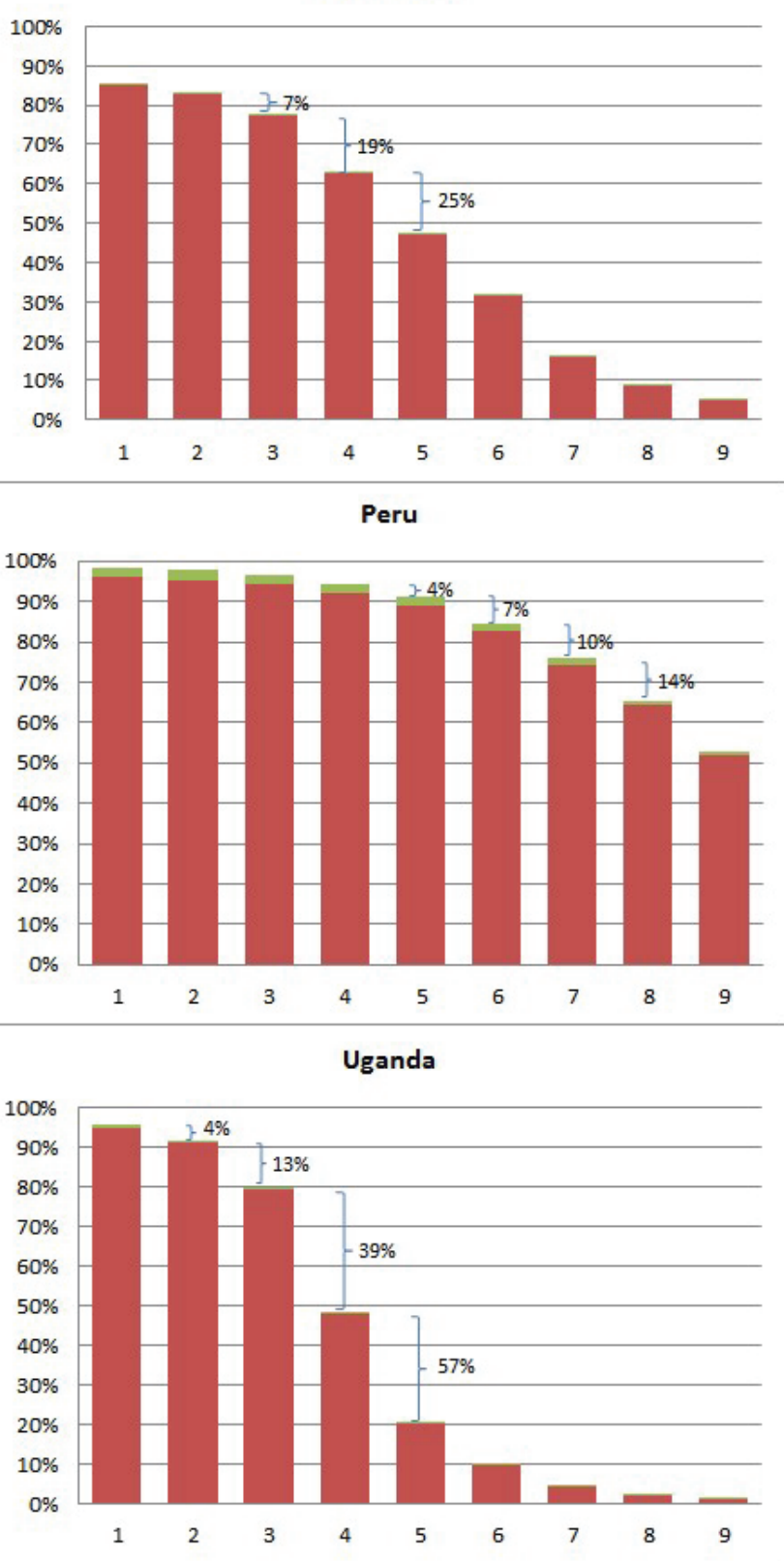

Figure 3. Cumulative percentage of women who had a birth in the five years preceding the DHS surveys by number of ANC visits and type of provider for their most recent live birth, in seven Countdown countries. 
Legend:

Blood pressure taken
Urine sample taken
Blood sample taken
Told about pregnancy complications

Note: In bangladesh, data on the first 3 interventions were not collected in the DHS survey.
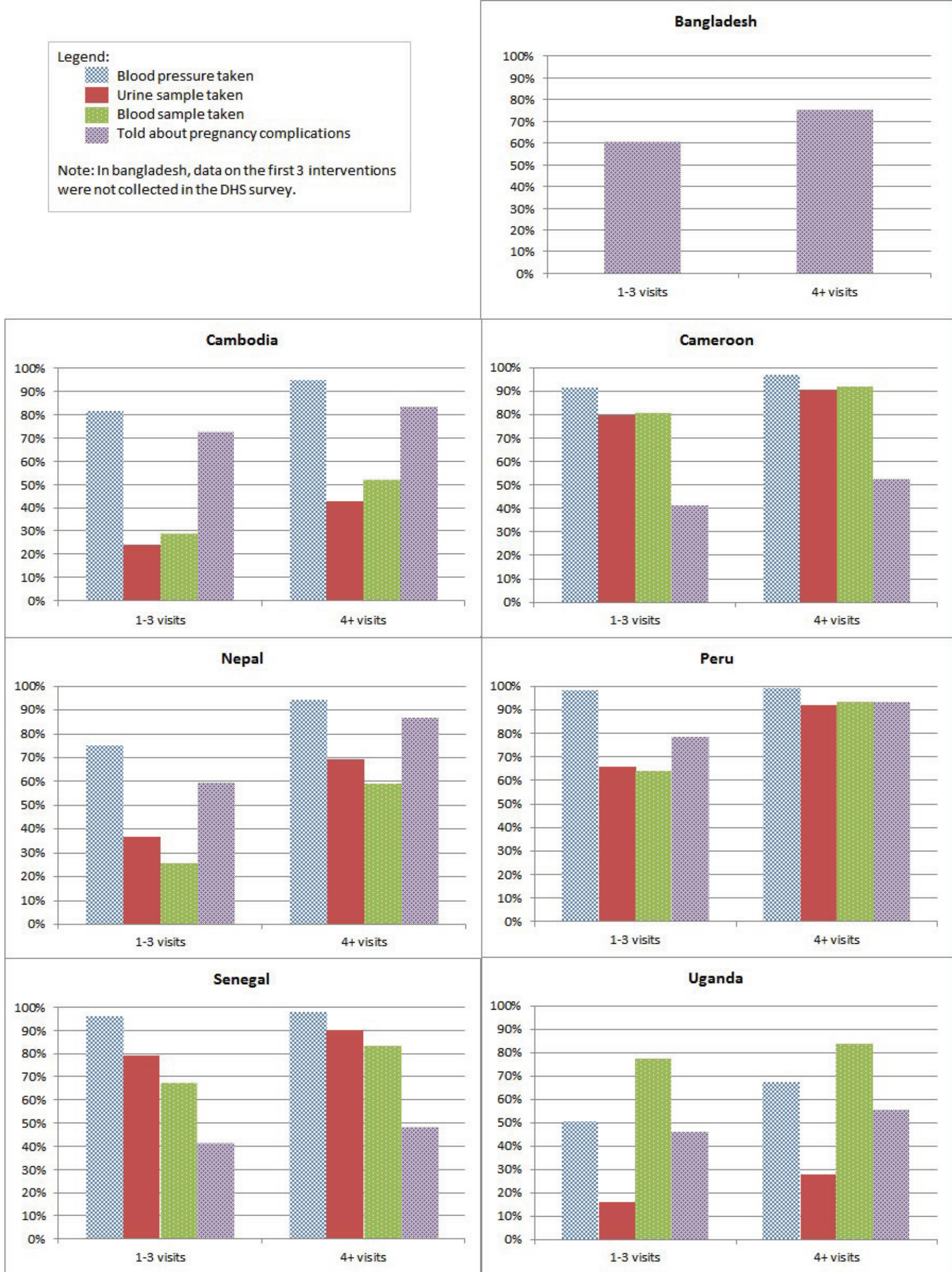

Figure 4. Percentage of women receiving content interventions during any ANC visit among women reporting one to three ANC visits or four or more ANC visits for their last live birth in the five years preceding the DHS survey, in seven Countdown countries. 
interventions than women who received care from unskilled providers (Table S3 in Online Supplementary Document). Stratification of women's reported content by household wealth quintile (Table S4 in Online Supplementary Document), showed that as women's wealth status increased, so did their proportions of reporting receipt of content interventions at least once during any visit.

We looked at gestational age at first ANC visit among women who reported receiving ANC visit for their most recent birth in the five years preceding the DHS survey. The results show that women who had their first ANC visit during the first trimester reported a higher number of visits overall (Figure S5 in Online Supplementary Document). In Cameroon and Uganda, the proportion of women who made their ANC debut during the second trimester is high relative to other countries. Nearly $40 \%$ of women in Cameroon and around half of the women in Uganda started ANC during their second trimester. In all seven countries, the proportion of women who report starting ANC in the third trimester is around 5\% with the exception of Uganda, where $13 \%$ of the women report receiving ANC for the first time in the third trimester; these women generally report three or less visits.

We present the distribution of women who reported receiving ANC visits by household wealth quintile in Figure 5. Wide disparities in the proportions of women reporting utilization exist across the wealth quintiles, except in Peru and Uganda. Top inequality exists where women in the richest wealth quintile are much better off than the rest; bottom inequality exists where women in the poorest wealth quintile are worse off than the rest of the women [35]. Inequality patterns differ by country. In Bangladesh, ANC utilization patterns clearly show top inequality, whereas in Cambodia and Nepal a pattern of top inequality begins to emerge only as the number of visits increases. The greatest disparities among countries are found in the proportions of women's reported visits by educational level (Figure S6.A in Online Supplementary Document). Women with the highest level of education report the highest proportions of visits. A pattern of top inequality emerges as the number of visits increases in all countries except Peru, where the inequality by woman's education is minimal and linear. Inequalities also exist in ANC utilization by place of residence (Figure S6.B in Online Supplementary Document). In all seven countries, women living in urban areas reported higher proportions of visits compared to their counterparts residing in rural areas. As a result of the drop off in utilization in Senegal and Uganda (Figure 2), the proportions of women who reported four or more visits show a considerable decline across all the wealth quintiles, educational levels and by urban-rural residence, in addition to a noticeable widening of the gap across categories of the three stratifiers as the number of visits reaches four or more ANC visits.

\section{Model-based results}

In the multivariable analysis, we sought to identify determinants of ANC initiation in Model A (zero visits vs one or more visits), and of frequency of visits in Model B (one to three visits vs four or more visits). Within each country, determinants predicting initiation of care and frequency of visits differed somewhat, except in Bangladesh where similar determinants predicted the outcome measures in both models at relatively similar odds ratios (OR). We present the results of Model B for the seven countries in Table 2; the results of model A and B for each country are found in in Tables S7A-G in Online Supplementary Document. When we entered the external environment factors, initially, place of residence had a significant effect on ANC in both models in all countries, except Uganda; however, as the subsequent levels were added to the models place of residence became insignificant. The exceptions are Bangladesh and Senegal where women residing in rural areas were less likely to report at least one visit, in Model A (OR: 0.67 and 0.62 , respectively) and less likely to report four or more visits in Model B (OR: 0.52 and 0.74, respectively), compared to women residing in urban areas. Generally, among women's predisposing characteristics, educational level was the strongest predictor of the outcome measures. In Peru, Senegal and Uganda, educational level was significantly positively associated with initiation of care (in Model A) only. In Bangladesh, Cambodia, Cameroon and Nepal, having any level of education significantly increased the odds of initiating ANC and having a higher frequency of visits, compared to having no level of education. Woman's age at last birth became less significant as the determinants from other levels were added into the Models. The only age group which recorded a significant effect on the outcome measures was the 20-34 years age group, where women in this age group in Cambodia, Nepal and Uganda were more likely to report having at least one ANC visit compared to women who were less than 20 years old (odds ratios ORs: $1.58,1.54 \& 1.62$, respectively). While in Cambodia, Cameroon and Peru, women aged 20-34 were more likely to have four or more visits compared to women who were less than 20 years old (ORs: $1.43,1.57 \& 2.48$, respectively). The effect of the other 'predisposing' characteristics (woman's occupational status, religion and marital status) were generally not significantly related to women's reported frequency of visits. Within the enabling resources, current partners' education affected the outcome measures positively in several countries. In Bangladesh, having a secondary or higher education and in Cambodia and Nepal having a secondary education increased the odds of initiat- 


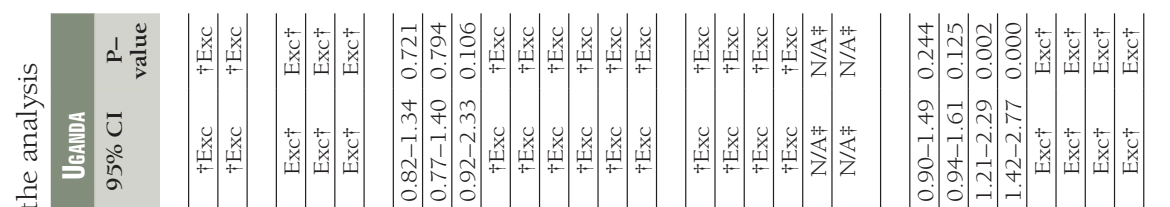

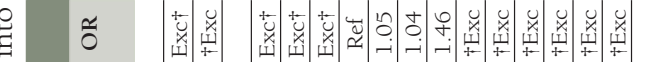

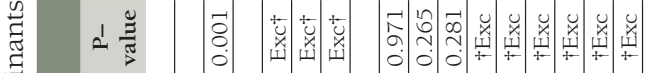
흘 홍 赵

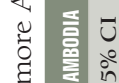

둥

+े

$\stackrel{\frac{n}{5}}{5}$

艾

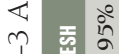

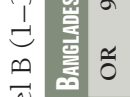

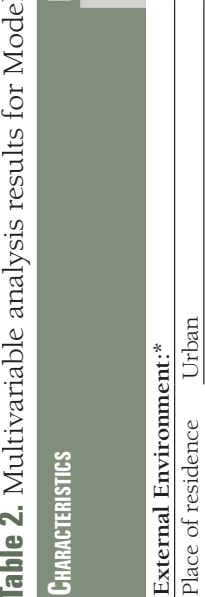

$\left(\begin{array}{c}\infty \\ \infty \\ \infty \\ 0\end{array}\right.$

-1
0
0
0

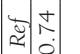

\begin{tabular}{c} 
\pm \\
\pm \\
\hdashline \\
0 \\
0 \\
0
\end{tabular}

势

\begin{tabular}{l|l}
1 \\
0 \\
0 \\
0
\end{tabular}

ॠ

(1)

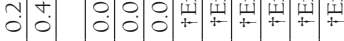

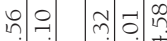

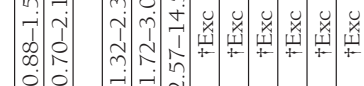

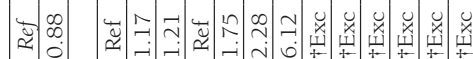

in

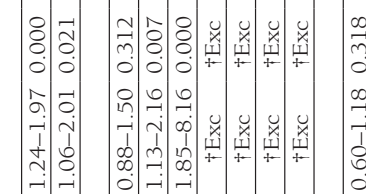

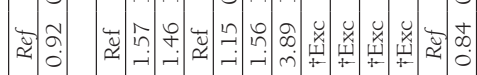

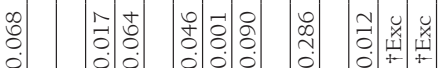

ㄴ.

(1)

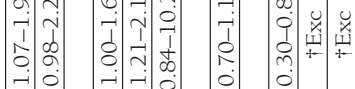

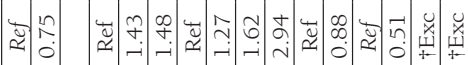

:

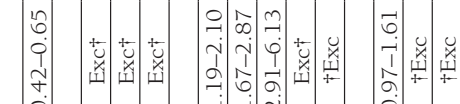

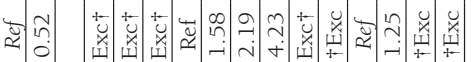

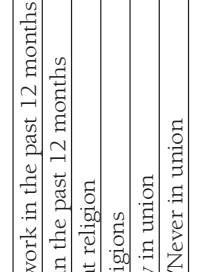

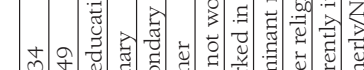

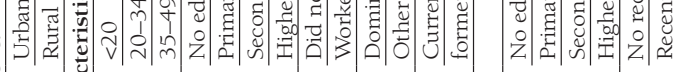

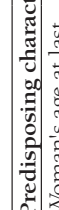

$\infty$

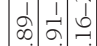

:

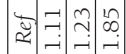

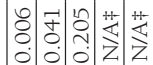

의 2

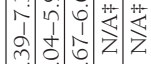

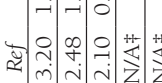

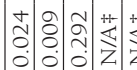

$\infty \infty$

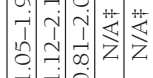

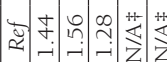

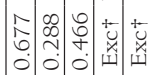

윙 융

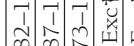

\section{$\begin{array}{llll}0 & 0 & 0 \\ 0 & 0 & 0 & 0 \\ 0 & 0 & 0\end{array}$}

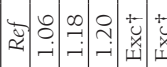

:

in $\infty$ - $\infty$

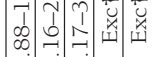

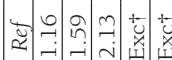

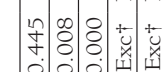

我

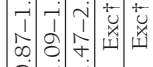

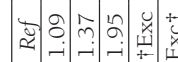

:

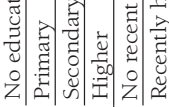

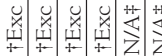

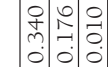

:

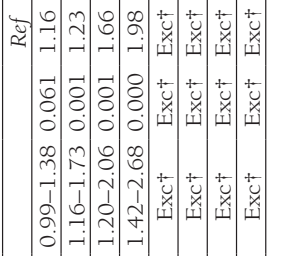

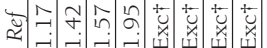

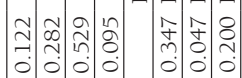

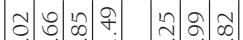

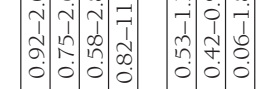

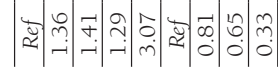

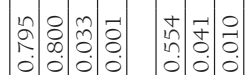

7. भु.

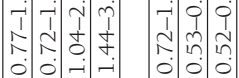

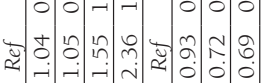

눈

우 요윳

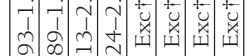

$0:=$

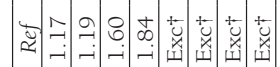

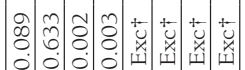

능워궈

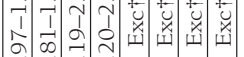

$0 .=7$

วิ)

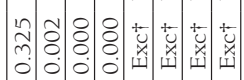

\section{iิ 1200}

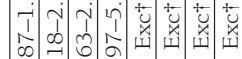

\section{0 in}

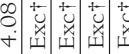

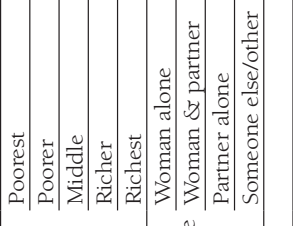

気

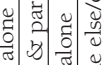

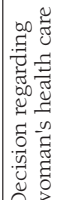

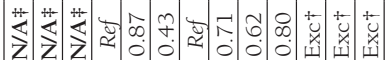

ปับ

跑

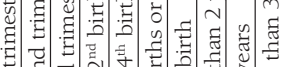

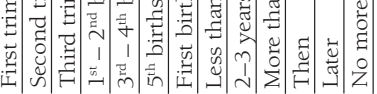

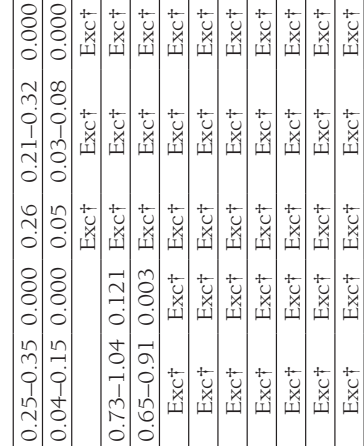

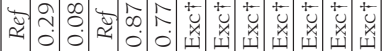

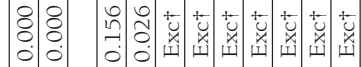

동.

ป

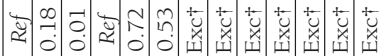

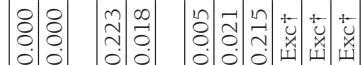

足:

กิ

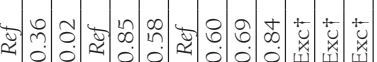

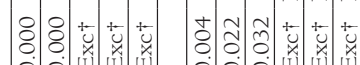

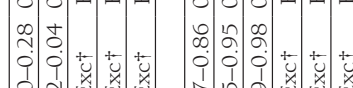

त:

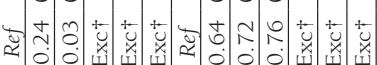

\&:

సै.

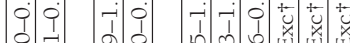

o. 0.0

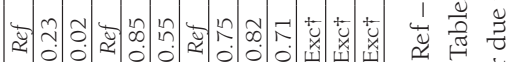

žn

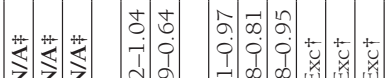
(र) ¿ 䒘 1
$\cup$
$己$ ํํㅇำ

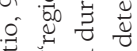

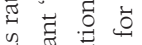

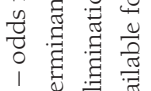

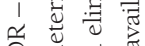
ज㻤

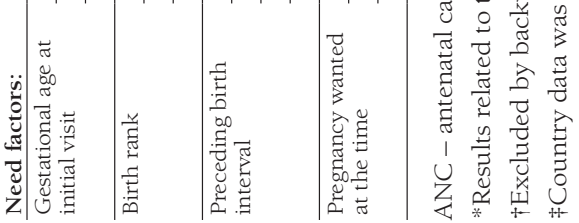




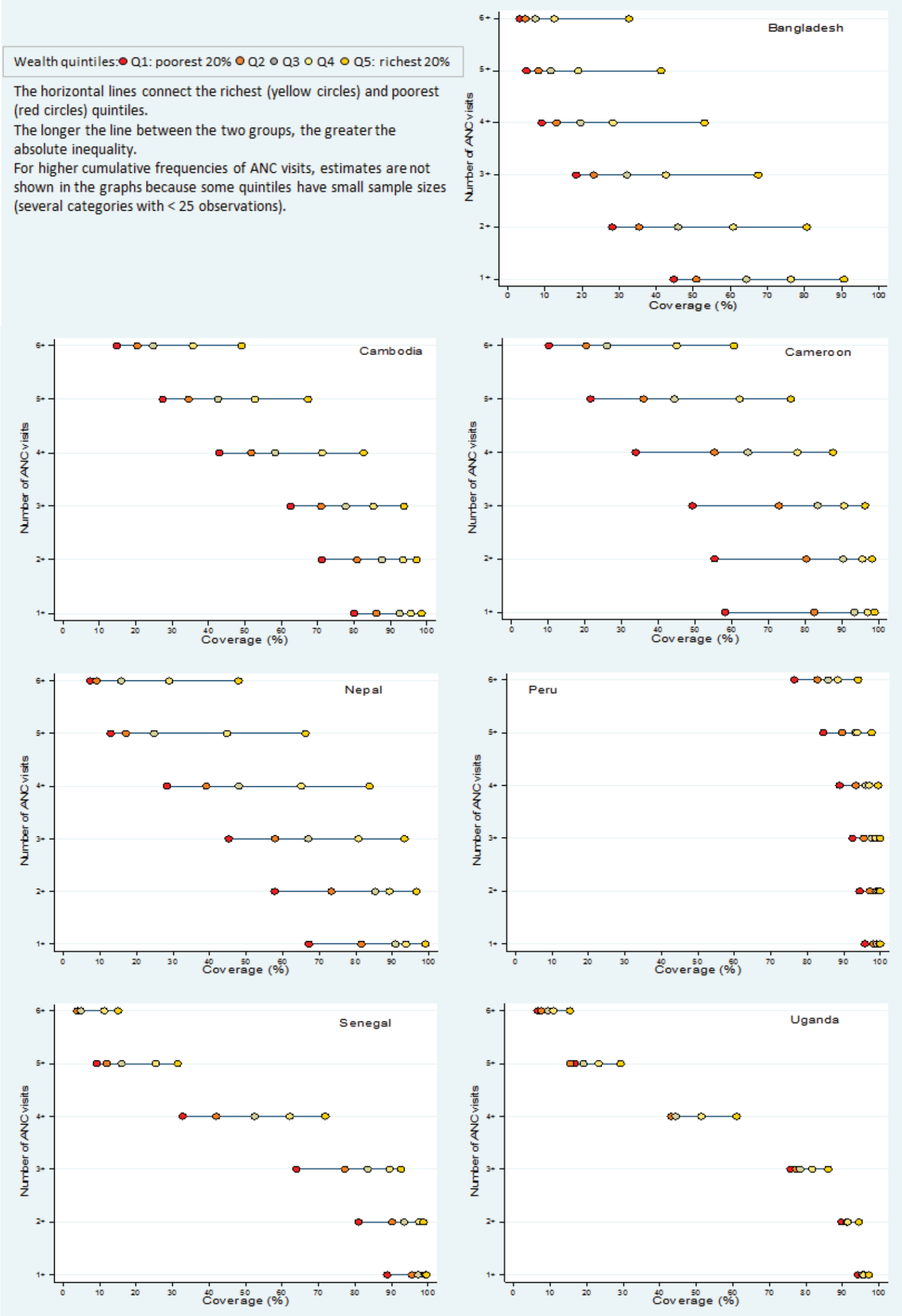

Figure 5. Percentage of women who had a live birth in the five years preceding the DHS surveys by number of ANC visits and household wealth quintiles, in seven Countdown countries. 
ing care (Model A) and the odds of having four or more visits compared to women whose current husbands have no education. Household wealth was the strongest predictor of the outcome measures in this level. Household wealth was positively associated with reporting four or more visits in all countries. The richest quintiles presented odds ratios of 2.4 to 6.1 and 1.7 to 3.1 compared to the poorest in Models A and B, respectively; with Senegal having the highest effect-odds ratio of 7.7 in Model A and Bangladesh having the highest effect-an odds ratio of 4.1 in Model B. Decision regarding the woman's health care was only significant in Cameroon (Model A), Nepal (both models) and Peru (Model B) and had a negative effect on the outcome measure. In the fourth and final hierarchical level, the "need" factors, women whose gestational age at initial visit was in the second or third trimester were significantly less likely to have four or more visits compared to women who had their initial visit in the first trimester. Birth rank had a significant negative association with initiation of ANC in Cambodia and Nepal; in Bangladesh, Peru and Senegal the negative effect of birth rank is significant at the $5^{\text {th }}$ birth or higher. Birth rank is also negatively associated with the frequency of ANC visits among women's $5^{\text {th }}$ birth or more in Bangladesh, Cambodia, Nepal, Peru and Senegal. Preceding birth interval was a strong predictor of the outcome measure in both models in Bangladesh, Cambodia, Cameroon and Nepal showing a negative association.

\section{Descriptive review of ANC-related national policies and programs}

Each of these seven countries has its own set of national policies, strategies and guidelines around health-related issues and ANC, specifically. Tables 3 and 4 summarize the information obtained through the questionnaire. Countries vary widely in terms of their ANC-related policies, programs, standards, and guidelines. Here we use selected examples to explore how these variations may have affected the ANC utilization patterns presented in the descriptive and multivariable analysis above. We describe this link with caution, because our data sets are not sufficiently complete or quantitative to determine directional causality.

Bangladesh and Peru, at the two extremes of ANC 1+ and ANC 4+ coverages among these seven countries, have comprehensive guidelines and policies related to ANC. Although, ANC utilization is relatively low in Bangladesh, trends in coverage of ANC 1+ and ANC 4+ have been increasing steadily since the early 1990s [13]. Unlike Bangladesh and the other five countries, the Peruvian government goes beyond the WHO guidelines of four ANC visits and recommends a minimum of six scheduled visits.

Both Senegal and Uganda show a distinct drop-off in ANC utilization between the third and fourth visits. In Senegal, several reproductive health-related policies were either updated or developed between 2002 and 2005, and one of the changes included moving from a standard of three to four ANC visits. In Uganda, the government has adopted a four-visit, focused ANC approach, and recently introduced guidelines addressing HIV/AIDS and prevention of mother-to-child transmission that refers to ANC as a platform for care and treatment. However, the reported number of visits by gestational age during the first ANC visit (Table S5 in Online Supplementary Document) showed that $66 \%$ and $13 \%$ of Ugandan women report initiating care during their second and third trimester, respectively, which inevitably means there is less time to complete the recommended number of visits prior to childbirth. The results of Uganda's multivariable analysis also show that as the gestational age at first ANC visit increases, women are significantly less likely to report receiving four or more ANC visits compared to three or fewer.

In Nepal, the proportion of women receiving care only from an unskilled provider was the highest among the seven countries, followed by Bangladesh. Our contextual information showed that both these countries had clear guidelines permitting unskilled providers to offer certain ANC services. The National Medical Standards for Reproductive Health guideline, adopted by the Nepali government in 2009 , states that in the absence of a skilled birth attendant in the facilities serving rural areas, a maternal and child health worker or a health assistant (categorized as unskilled providers in our study) can provide ANC services [36]. With $90 \%$ of our sample of Nepali women residing in rural areas, high proportions of women may have only had access to unskilled providers offering ANC services. Furthermore, some reports from Nepal refer to unskilled providers such as health assistants, auxiliary health workers, maternal and child health workers, and village health workers as trained professionals [37]. In Bangladesh, similar to Nepal, the majority of women reside in rural areas (around 75\% of our sample), which are served by a complex network of public health facilities offering ANC services by skilled and unskilled providers. At community level, providers now considered unskilled for ANC, historically provided services at primary facilities and household level through both government and non-government agencies [38].

\section{DISCUSSION}

The globally-measured ANC indicators, ANC 1+ and ANC $4+$, need to be accompanied by more detailed analysis of ANC utilization patterns in each country in order to unpack the underlying factors and inequalities that play a role in women's uptake of ANC services.

We intentionally selected countries for analysis from different world regions and with varying levels of ANC 1+, ANC 
Table 3. Summary of policies and programs related to ANC, in seven Countdown countries

\begin{tabular}{|c|c|c|c|}
\hline & SeleEtion of national poligies and thelr reference to ANC & $\begin{array}{l}\text { Polcies \& EFFORTS tO TACKIE } \\
\text { INEQUTIIES }\end{array}$ & $\begin{array}{l}\text { ANC-RELATED CAMPAIGNS OR } \\
\text { COMMUNICATION EFFORTS }\end{array}$ \\
\hline Bangladesh & $\begin{array}{l}\text { National Maternal Health Strategy-2001: } \\
\text { - Specifies the supply of equipment for ANC, the delivery of care and a } \\
\text { monitoring checklist. } \\
\text { - Outlines interaction with pregnant women and their families to ensure } \\
\text { ANC uptake and popularization of service delivery mechanisms as well } \\
\text { as the use of ANC for birth preparedness. } \\
\text { Health, Population and Nutrition Sector Development Plan (HPNSDP), 2011- } \\
2016 \text { : } \\
\text { - ANC mentioned as a key service in emergency obstetric care needs and } \\
\text { management. } \\
\text { - Specifically mentions distribution of folic acid/and iron supplementa- } \\
\text { tion. } \\
\text { National Plan of Action for Adolescent Sexual and Reproductive Health, 2013: } \\
\text { - Specifically published to tackle the major concern of teenage pregnan- } \\
\text { cies which make up around 30\% of adolescents aged 15-19 y old. }\end{array}$ & $\begin{array}{l}\text { The HPNSDP-2011-2016 pri- } \\
\text { oritizes the improvement of } \\
\text { ANC by: } \\
\text { - Emphasizing maternal, new- } \\
\text { born, child and adolescent } \\
\text { health interventions/services } \\
\text { in urban slums, hard to } \\
\text { reach and low performing } \\
\text { areas. } \\
\text { - Prioritizing areas of high ma- } \\
\text { ternal mortalities and geo- } \\
\text { graphically \& socially disad- } \\
\text { vantaged population. }\end{array}$ & $\begin{array}{l}\text { Available through various } \\
\text { types: } \\
\text { - Television and radio pro- } \\
\text { grams. } \\
\text { - Mass communication dur- } \\
\text { ing the Safe Motherhood } \\
\text { days when ANC is promot- } \\
\text { ed along with other servic- } \\
\text { es. } \\
\text { - Posters and pamphlets } \\
\text { available at health facilities. }\end{array}$ \\
\hline Cambodia & $\begin{array}{l}\text { Health Sector Strategic Plan for 2008-2015: } \\
\text { - Plans to scale up access to and coverage of health services, especially } \\
\text { comprehensive reproductive, maternal, newborn and child health ser- } \\
\text { vices. } \\
\text { Safe Motherhood Clinical Management Protocols for Referral Hospital-June } \\
1013 \& \text { Safe Motherhood Clinical Management Protocols for Health Centre- } \\
\text { July 2010: } \\
\text { - Provide technical updates regarding frequency of ANC visits (from 2+ } \\
\text { to 4+), timing (as early as knowing the missing period), and additional } \\
\text { services (screening). }\end{array}$ & $\begin{array}{l}\text { The Health Sector Strategic Plan } \\
-2008-2015 \text { has pro-poor } \\
\text { policies including: } \\
\text { - Pro-poor health financing } \\
\text { systems } \\
\text { - Exemptions for the poor } \\
\text { - Expansion of the health eq- } \\
\text { uity funds } \\
\text { - Health insurance }\end{array}$ & $\begin{array}{l}\text { To promote early ANC visits } \\
\text { an ANC campaign took place } \\
\text { in } 2009 \text { using both mass me- } \\
\text { dia and interpersonal com- } \\
\text { munication in selected geo- } \\
\text { graphical areas. }\end{array}$ \\
\hline Cameroon & $\begin{array}{l}\text { Prenatal care centres (Soins Prenataux Recentres)-2006 } \\
\text { - Includes change from the focus on the number of visits to the quality } \\
\text { of the visit. } \\
\text { Prevention of Mother to Child Transmission of HIV-November } 2008\end{array}$ & $\begin{array}{l}\text { A project initiated by the } \\
\text { World Bank in } 14 \text { districts to } \\
\text { test performance-based fi- } \\
\text { nancing addresses some as- } \\
\text { pects of inequity. }\end{array}$ & No specific efforts noted \\
\hline Nepal & $\begin{array}{l}\text { National Health Policy - 1991: } \\
\text { - Adopted the safe motherhood approach with the Safe Motherhood Pro- } \\
\text { gram being a priority. } \\
\text { Safe Motherhood Policy-1996: } \\
\text { - Focuses on improving maternal health in a holistic way }\end{array}$ & No specific efforts noted. & $\begin{array}{l}\text { - The Government imple- } \\
\text { mented a communication } \\
\text { strategy. } \\
\text { - ANC-related messages are } \\
\text { broadcast through radio. }\end{array}$ \\
\hline
\end{tabular}

National Policy on Skilled Birth Attendants NPSBA)-2006

National Medical Standard for Reproductive Health-2009:

- An updated version of the National Maternity Care Guidelines (NMCG) which was released in 2006.

- A standard reference document for essential clinical materials and tools in support of patient care using the latest evidence in maternal and neonatal care.

- Uses the concepts of focused antenatal care.

- Emphasis is on every pregnant woman being at risk, birth preparedness and complication readiness, providing quality rather than quantity of antenatal care.

Peru Comprehensive Health Insurance (The Seguro Integral de Salud (SIS)) - 2001:

- Aims to protect the health of Peruvians who do not have health insurance, prioritizing those vulnerable populations who are in poverty or extreme poverty.

Budgeting for results (Presupuesto por Resultados) - 2008:

- It proposes action based on critical problem solving and includes Strategic Programs such as the one for Mother and Newborn (which was established for women in extreme poverty \& no health insurance).

Technical document: National Strategic Plan for Reduction of Maternal and Neonatal Mortality (RN No. 207-2009)

Technical Guides: Intervention Model to improve Access, Quality and Use of facilities that provide obstetric and neonatal functions (RM No. 223-2009/ MINSA)

- provides strategies to improve availability, accessibility and use of facilities.

Technical Standard for the comprehensive care of maternal health (RM No. 827-2013/MINSA)

- Establishes the technical requirements and administrative procedures, based on scientific evidence, that allow to deliver quality care in preparation for pregnancy, refocused prenatal care, institutional and skilled delivery care and postpartum care.

- The Seguro Integral de Salud
(SIS)-2001

- The Mother and Newborn Strategic Program

- The Technical Standard for Vertical Delivery with Attention to Intercultural Adaption: intended to improve access for Andean and Amazonian women of childbearing age.

- The establishment of Maternal Waiting homes to increase access to delivery care in health facilities.
Different media used to communicate importance of ANC 
Table 3. Continued

\begin{tabular}{|c|c|c|c|}
\hline & Selection of national policies and thelr reference to ANC & $\begin{array}{l}\text { Policies \& EFFORTS tO taCKIE } \\
\text { INEQUITIES }\end{array}$ & $\begin{array}{l}\text { ANC-RELATED CAMPAIGNS OR } \\
\text { COMMUNICATION EFFORTS }\end{array}$ \\
\hline Senegal & $\begin{array}{l}\text { National Program for the Prevention of Maternal Mortality (Programme Na- } \\
\text { cional de Prevention de la Mortalite Maternelle)-1990 } \\
\text { Politique de Santé et d'Action Sociale (Health Policy and Social Action)-1995 } \\
\text { - Placed reproductive health as one of the cornerstones. } \\
\text { Population Policy Statement (Déclaration de Politique de Population) } \\
\text { - Established in } 1998 \text { \& updated in } 2002 \text { to be consistent with the ICPD. } \\
\text { National Program of Reproductive Health (Programme Nacional de santé de } \\
\text { la Reproduction)-2002 } \\
\text { A multi-sectoral roadmap } \\
\text { - Developed to accelerate the reduction of maternal and neonatal mortal- } \\
\text { ity in order to achieve MDGs } 4 \& 5 \text {. }\end{array}$ & $\begin{array}{l}\text { The national strategy for all } \\
\text { women of reproductive age has } \\
\text { elements for making services } \\
\text { available to all-geographically, } \\
\text { financially, socio-culturally, } \\
\text { and to all religious groups } \\
\text { through: } \\
\text { - Increasing points of service } \\
\text { delivery. } \\
\text { - Provision of minimum pack- } \\
\text { age of reproductive health } \\
\text { services at health facilities. } \\
\text { - Adjusting the fees/costs ac- } \\
\text { cording to people's abilities }\end{array}$ & $\begin{array}{l}\text { - Government conducted } \\
\text { nationwide scale up cam- } \\
\text { paign with radio and televi- } \\
\text { sion spots on malaria pre- } \\
\text { vention with SP and use of } \\
\text { ITNs. } \\
\text { - NGOs support this cam- } \\
\text { paign by broadcast general } \\
\text { messages on antenatal care } \\
\text { through local-community } \\
\text { radio. }\end{array}$ \\
\hline
\end{tabular}

Uganda The National Policy Guidelines and Service Standards for Sexual and Reproductive Health and Rights-2012 ( $3^{\text {rd }}$ update)

A voucher scheme for preg- • Radio messaging on particnant women is being piloted in ular aspects of ANC, eg,

- Sets rules and regulations governing reproductive health services in- a few areas.

cluding antenatal services

- Outlines tasks that guide service provision and describe aspects of ANC services

- Emphasizes integration of services such as access to services for sexually transmitted infections and HIV/AIDS services at the ANC clinic

Integrated National Guidelines on Antiretroviral Therapy, Prevention of Moth-

er to Child Transmission and on Infant \& young Child feeding-2011

- Facilitates integration of services and to promote a family-centered approach for HIV and AIDS care and treatment.

- ANC is recognized as a platform for this care and treatment.

ANC - antenatal care, SP - sulfadoxine-pyrimethamine, ITN - Insecticide-treated bednet, NGO - non-governmental organization, ICPD - International Conference on Population and Development, MDG - Millennium Development Goals, HIV - human immunodeficiency virus, AIDS - Acquired Immune Deficiency Syndrome.

4+ and skilled birth attendance coverage. Skilled birth attendance is lowest, at 32\% and 36\%, in Bangladesh and Nepal, respectively [13]; in addition to having the lowest proportions of one or more and four or more ANC visits, our results also showed that these two Asian countries reported the highest prevalence of ANC provision by an unskilled provider. However, local definitions of what constitutes a skilled provider seem to vary in these two countries as described in the descriptive review of national policies and programs.

Nevertheless, the majority of women in the seven Countdown countries reported receiving care from a skilled provider at least once. The reported content interventions, on the other hand, require more attention. Even in Peru, where over $90 \%$ of women reported receiving four or more visits, evidence-based content was highest relative to other countries yet not universal. Regardless of countries' diverse settings, women who reported four or more ANC visits, who received care from a skilled provider at least once and were better off in terms of household wealth, reported receiving a higher proportion of each of the four content interventions. Similar results were also presented by Hodgins et al (2014), who looked at DHS data on content interventions of ANC visits from countries [31]. In their analysis, the proportion of content interventions (out of eight) among women who reported four or more visits ranged from $32 \%$ to $85 \%$ in the 41 countries and the overall average was $60 \%$ [31]. These relationships need to be explored further at the country level to understand whether content interventions are not being provided during ANC visits or are being postponed to later during the pregnancy, resulting in missed opportunities for women who report a low number of visits. Or, on the contrary, the perceived usefulness and quality of the interventions offered at health care facilities may play a role in women's decisions about whether to return for subsequent visits. We did not consider the health care facilities providing the ANC services in our quantitative analysis, yet this may play an important role in women's ANC utilization patterns especially if the quality of care is perceived as poor. Powell-Jackson and colleagues looked at the quality of ANC services in the private commercial sector, private not-for-profit sector, public sector and home from DHS data in 46 low- and middle-income countries [39]. The content of care score was worst in home-based care, where women received the least number of ANC services, followed by both the public and private commercial sectors with similar scores and the private not-for-profit had the highest ANC content score. The researchers conclude that the private commercial and 
Table 4. Summary of national standards and guidelines for ANC, in seven Countdown countries

\begin{tabular}{|c|c|c|c|c|c|c|}
\hline & $\begin{array}{l}\text { RECOMMENDED NUMBER OF ANC } \\
\text { VISITS }\end{array}$ & $\begin{array}{l}\text { PreS- } \\
\text { ENGE OF } \\
\text { GUIDELINES } \\
\text { FOR VISIT } \\
\text { CONIENT }\end{array}$ & $\begin{array}{l}\text { Where ANC SERVICES ARE } \\
\text { PROVIDED }\end{array}$ & Who PROVIDES tHe ANC SERVICES & Presence of user feES & $\begin{array}{l}\text { INCENTINES FOR WOMEN'S } \\
\text { UTHLIZATION }\end{array}$ \\
\hline Bangladesh & $\begin{array}{l}\text { Follows the WHO } \\
\text { recommendation: } \\
\text { - } 1^{\text {st }} \text { visit: before } 16 \\
\text { weeks. } \\
\text { - } 2^{\text {nd }} \text { visit: } 24-28 \text { weeks. } \\
\text { - } 3^{\text {rd }} \text { visit: } 30-32 \text { weeks. } \\
\text { - } 4^{\text {th }} \text { visit: } 36-38 \text { weeks. }\end{array}$ & Present & $\begin{array}{l}\text { Provided at both } \\
\text { private sector and } \\
\text { public sector (primary, } \\
\text { secondary and tertiary } \\
\text { facilities) and through } \\
\text { NGOs. Home-based } \\
\text { ANC may be provided } \\
\text { in rural areas. }\end{array}$ & $\begin{array}{l}\text { In urban areas and the } \\
\text { private sector, doctors } \\
\text { usually provide ANC. In } \\
\text { rural areas there is a wider } \\
\text { array of skilled and } \\
\text { unskilled providers who } \\
\text { offer ANC services. }\end{array}$ & $\begin{array}{l}\text { No public sector } \\
\text { fees. Private } \\
\text { facilities charge } \\
\text { fees for service. }\end{array}$ & $\begin{array}{l}\text { In some Upazila } \\
\text { Health Centers } \\
\text { (public facilities) } \\
\text { patients receive } \\
\text { transportation cost. }\end{array}$ \\
\hline Cambodia & $\begin{array}{l}\text { Follows the WHO } \\
\text { recommendation: } \\
\text { - } 1^{\text {st }} \text { visit: before } 16 \\
\text { weeks (or as soon as } \\
\text { possible after a missed } \\
\text { menstrual period). } \\
\text { - } 2^{\text {nd }} \text { visit: } 24-28 \text { weeks. } \\
\text { - } 3^{\text {rd }} \text { visit: } 30-32 \text { weeks. } \\
\text { - } 4^{\text {th }} \text { visit: } 36-38 \text { weeks. }\end{array}$ & Present & $\begin{array}{l}\text { Provided at health } \\
\text { centers (primary } \\
\text { facilities) or hospitals } \\
\text { (tertiary level). }\end{array}$ & $\begin{array}{l}\text { Types of providers \& } \\
\text { services are the same in } \\
\text { urban and rural public } \\
\text { facilities. Services in private } \\
\text { facilities depend on ability } \\
\text { to pay. ANC services are } \\
\text { generally provided by } \\
\text { midwives. }\end{array}$ & $\begin{array}{l}\text { Public facilities } \\
\text { have user fee } \\
\text { schemes. Private } \\
\text { sector facilities } \\
\text { have a fee-for-ser- } \\
\text { vice. }\end{array}$ & $\begin{array}{l}\text { Some schemes offer } \\
\text { indirect incentives } \\
\text { through: } \\
\text { - Health equity } \\
\text { fund } \\
\text { - Voucher scheme } \\
\text { linking ANC } \\
\text { services to other } \\
\text { MCH services. }\end{array}$ \\
\hline Cameroon & $\begin{array}{l}\text { Recommends four visits: } \\
\cdot 1^{\text {st }} \text { visit at } 1-16 \text { weeks } \\
\text { amenorrhea. } \\
\text { - } 2^{\text {nd }} \text { visit at } 28 \text { weeks. } \\
\text { - } 3^{\text {rd }} \text { visit at } 32 \text { weeks. } \\
\text { - } 4^{\text {th }} \text { visit at } 36 \text { weeks. }\end{array}$ & $\begin{array}{l}\text { None } \\
\text { provided }\end{array}$ & $\begin{array}{l}\text { Present at all health } \\
\text { facilities. }\end{array}$ & $\begin{array}{l}\text { Providers do not vary } \\
\text { according to public/private } \\
\text { sector or to rural/urban } \\
\text { areas. } \\
\text { ANC services are provided } \\
\text { by various skilled \& } \\
\text { unskilled providers and at } \\
\text { various workstations in one } \\
\text { facility. }\end{array}$ & $\begin{array}{l}\text { Both the public } \\
\text { and private sector } \\
\text { charge fees at } \\
\text { different rates. }\end{array}$ & $\begin{array}{l}\text { No incentives } \\
\text { available }\end{array}$ \\
\hline Nepal & $\begin{array}{l}\text { Recommends four visits: } \\
\text { - } 1^{\text {st }} \text { visit at } 4 \text { months } \\
\text { - } 2^{\text {nd }} \text { visit at } 6 \text { months } \\
\text { - } 3^{\text {rd }} \text { visit at } 8 \text { months } \\
\text { - } 4^{\text {th }} \text { visit at } 9 \text { months }\end{array}$ & Present & $\begin{array}{l}\text { In rural areas, ANC is } \\
\text { provided at sub-health } \\
\text { posts, health posts and } \\
\text { district hospitals. In } \\
\text { urban areas, ANC is } \\
\text { provided at private } \\
\text { clinics and maternity } \\
\text { hospitals. }\end{array}$ & $\begin{array}{l}\text { All service providers } \\
\text { should be skilled birth } \\
\text { attendants (these include } \\
\text { nurses and doctors). If } \\
\text { these skilled providers are } \\
\text { not available at Sub-health } \\
\text { posts and out-reach } \\
\text { clinics, then MCH Workers } \\
\text { can provide ANC services. }\end{array}$ & $\begin{array}{l}\text { No public sector } \\
\text { fees. Private sector } \\
\text { charges vary. }\end{array}$ & $\begin{array}{l}\text { Incentives provided } \\
\text { to women who } \\
\text { complete } 4 \text { ANC } \\
\text { visits and have an } \\
\text { institutional } \\
\text { delivery. }\end{array}$ \\
\hline Peru & $\begin{array}{l}\text { Recommends a minimum } \\
\text { of } 6 \text { visits: } \\
\text { - } 1^{\text {st }} \text { visit: at less than } 14 \\
\text { weeks } \\
\text { - } 2^{\text {nd }} \text { visit: } 14-21 \text { weeks } \\
\text { - } 3^{\text {rd }} \text { visit: } 22-24 \text { weeks } \\
\text { - } 4^{\text {th }} \text { visit: } 25-32 \text { weeks } \\
\text { - } 5^{\text {th }} \text { visit: } 33-36 \text { weeks } \\
\text { - } 6^{\text {th }} \text { visit: } 37-40 \text { weeks }\end{array}$ & Present & $\begin{array}{l}\text { Most ANC services are } \\
\text { provided through the } \\
\text { network of } 8000 \text { public } \\
\text { facilities. Home visits } \\
\text { are made when women } \\
\text { miss their scheduled } \\
\text { visit. }\end{array}$ & $\begin{array}{l}\text { Service providers are } \\
\text { mainly skilled. Unskilled } \\
\text { providers are usually } \\
\text { involved in the health team } \\
\text { particularly at the first level } \\
\text { of the health system. }\end{array}$ & $\begin{array}{l}\text { Fees depend on } \\
\text { different funding } \\
\text { sources. }\end{array}$ & $\begin{array}{l}\text { Specific program } \\
\text { created in } 2005, \\
\text { provides program } \\
\text { grants for direct } \\
\text { transfers to benefit } \\
\text { the poorest } \\
\text { families, rural and } \\
\text { urban. }\end{array}$ \\
\hline Senegal & $\begin{array}{l}\text { Recommends at least } 4 \\
\text { visits: } \\
\text { - } 1^{\text {st }} \text { visit at } 3 \text { months } \\
\text { - } 2^{\text {nd }} \text { visit at } 6 \text { months } \\
\text { - } 3^{\text {rd }} \text { visit at } 8 \text { months } \\
\text { - } 4^{\text {th }} \text { visit at } 9 \text { months }\end{array}$ & Present & $\begin{array}{l}\text { Provided through } \\
\text { health huts, health } \\
\text { posts, maternity centers } \\
\text { or hospitals and private } \\
\text { clinics. }\end{array}$ & $\begin{array}{l}\text { Standards and protocols } \\
\text { stipulate that only skilled } \\
\text { providers can provide ANC } \\
\text { services at both public and } \\
\text { private facilities }\end{array}$ & $\begin{array}{l}\text { Both public and } \\
\text { private sector facil- } \\
\text { ities charge fees } \\
\text { but at different } \\
\text { rates. }\end{array}$ & $\begin{array}{l}\text { Insecticide-treated } \\
\text { bednets are } \\
\text { provided to } \\
\text { pregnant women. }\end{array}$ \\
\hline Uganda & $\begin{array}{l}\text { Recommends four } \\
\text { focused ANC visits: } \\
\text { - } 1^{\text {st }} \text { visit: } 0-16 \text { weeks } \\
\text { (after two missed } \\
\text { periods). } \\
\text { - } 2^{\text {nd }} \text { visit: } 16-28 \text { weeks. } \\
\text { - } 3^{\text {rd }} \text { visit: } 28-36 \text { weeks. } \\
\text { - } 4^{\text {th }} \text { visit: after } 36 \text { weeks. } \\
\text { - } 4^{\text {th }} \text { visit: after } 36 \text { weeks. }\end{array}$ & Present & $\begin{array}{l}\text { Provided at hospitals, } \\
\text { health centers, and } \\
\text { sometimes at outreach } \\
\text { clinics. }\end{array}$ & $\begin{array}{l}\text { Skilled providers provide } \\
\text { ANC services in all } \\
\text { facilities. Unskilled } \\
\text { providers such as } \\
\text { community health workers } \\
\text { \& village health team } \\
\text { members can provide } \\
\text { information. Nursing } \\
\text { assistants \& nurse aids are } \\
\text { being phased out. }\end{array}$ & $\begin{array}{l}\text { No public sector } \\
\text { fees. In Private } \\
\text { not-for-profit } \\
\text { facilities fees are } \\
\text { subsidized. Private } \\
\text { for profit sector } \\
\text { generally does not } \\
\text { subsidize ANC } \\
\text { except for } \\
\text { immunization. }\end{array}$ & $\begin{array}{l}\text { Mama Kit of } \\
\text { essential supplies to } \\
\text { use during delivery } \\
\text { (gloves, protective } \\
\text { sheets, baby } \\
\text { receiving sheet, } \\
\text { soap) are provided } \\
\text { to pregnant } \\
\text { women. }\end{array}$ \\
\hline
\end{tabular}

ANC - antenatal care, WHO - World Health Organization, NGO - non-governmental organization, MCH - maternal and child health. 
public sectors are both very diverse and show lots of variation in quality of care, possibly depending on the economic status of women seeking ANC care [39].

In order to ensure high coverage of accessible and equitable ANC services, programs and policies need to focus on women with low levels of education, living in poor and rural households. Our findings indicate that household wealth is an important determinant of ANC initiation in all seven countries, and of the overall frequency of visits in all countries except Peru. This is consistent with a systematic review of the relevant literature [27]. Our multivariable analysis results showed that women who come from poorer households are less likely than richer women to initiate care, and among those who do seek ANC, less likely to have four or more visits. These multivariable results complement the results of the equity analysis, and highlight the need to address financial barriers to accessing ANC services. ANC services are offered by the public sector free of charge in Bangladesh, Nepal and Uganda, and yet utilization is relatively low. Unexpected fees for prescribed medications or tests, and indirect costs related to transportation to the facility, have been associated with women's choices of health care services, and need to be considered [28]. The exceptional case of Peru may reflect its unique combination of political will, economic growth, broad societal participation, pro-poor strategies and increased spending in health and related sectors in the last two decades, which led to reduction in socioeconomic inequalities in health and significant progress in coverage of RMNCH interventions especially among the most deprived groups and areas of the country [40].

Education allows women to be more autonomous, more knowledgeable about health care services, and therefore to exert greater control over health-related decisions. We would therefore expect women's education to have a positive influence on the initiation and frequency of ANC visits $[19,20,27]$, and this is supported by our results. The wide disparities in ANC utilization by levels of women's education may also be due to the uneven distribution of women within each category; women who have attained higher levels of education are fewer in number and generally better off than those who report having low or no education. The results of the multivariable analysis showed that education was a significant determinant for initiating ANC, and to a lesser extent, for reporting four or more ANC visits. Similar to the results of Guliani and colleagues [19], who looked at the use of ANC services and their frequency across 32 low income countries, the association of women's education was stronger with the initiation of ANC visits than with the overall number of visits. This may be because women with no education are not included in the second model, which looks at the frequency pattern of utilization [19].
The equity analysis showed that women residing in rural areas have lower proportions of ANC utilization than women residing in urban areas, and our policy data suggested important differences in services and providers in urban and rural areas in most country settings. We were therefore surprised that urban-rural residence emerged as a significant determinant of ANC visits only in Bangladesh and Senegal. A systematic review looking at early use of ANC services and type of residence concluded that the association was not consistent [41], hence further country analysis is required to identify the contextual factors that affect ANC use. A study looking at contextual influences of 13 sub-regions in Nepal on women's ANC patterns identified important sub-regional variations in ANC use, which need to be taken into consideration at the policy-making level [42]. Our findings reinforce the importance of regional differences in ANC utilization within countries, and suggest that further analysis of this relationship is likely to generate information useful for ANC program planning.

We collected some information on barriers to ANC utilization from national surveys or ethnographic studies through our key informant interviews, but were often unable to obtain full and relevant information. Qualitative studies exploring barriers to antenatal care are available in the literature, and can contribute to the interpretation of our findings. In Bangladesh, despite multiple maternal health policies and an extensive array of public sector ANC facilities, women are not utilizing ANC services as recommended. This has been attributed by some to women's perception that pregnancy is a normal event that does not need medical care and interventions [43]. In Cambodia, five types of barriers to maternal health care use have been identified as needing to be addressed to increase ANC utilization: financial, physical, cognitive, organizational and psychological/socio-cultural [44]. One study reported that the use of ANC services by pregnant women in Nepal was greatly influenced by mothers-in-law [45]; this is corroborated by our multivariable results showing a negative association between women's reports that they are not responsible for health care decisions and the frequency of visits. Another study reports that mothers in Uganda viewed ANC services as deficient, and are dissatisfied with the perceived quality of the interventions offered during visits [46]. WHO has identified several barriers to the provision of quality ANC, including perceptions of poor quality of care, distance, cost, stigma, social and traditional influences, perceptions that pregnancy is a healthy state that does not need specific care, and disrespect for and abuse of women in health service settings [47]. Furthermore, a systematic scoping review performed to understand what women seek during pregnancy, found that across diverse settings, having a positive pregnancy experience was what 
mattered to pregnant women and this was characterized by four themes: preserving physical and sociocultural normality; maintaining a healthy pregnancy for mother and baby; effective transition to progressive labour and birth; and ensuring positive motherhood [48].

Our study has some limitations that need to be kept in mind when interpreting the results. DHS data are collected on ANC-related questions, only, for women's most recent live birth in the five years preceding the survey. Hence, pregnancies resulting in a miscarriage or a stillbirth are excluded and no data on the ANC utilization patterns of these pregnancies is collected; data which may provide important insights to the patterns and quality of care in these cases specifically. Furthermore, the DHS data we use is from interviews with women and their responses to the frequency of ANC visits, types of providers seen, and content interventions received for their most recent live birth. As a result, there may be potential recall bias, an issue which is receiving increased awareness in mothers' reports of services received [49]. Women may also be biased in their reports of the type of provider from whom they received care, especially in settings where several types of providers offer ANC care. Other limitations related to the type of provider are the fact that the DHS data cannot tell us the type of provider visited during each of the woman's ANC visit and that the choice of providers may be restricted to who is available at the health care facility in the community. We report on content received during any ANC visit, and while it does imply a minimum level of quality of care, we are unable to confirm it, because the DHS does not assess whether the content interventions were offered in a proper and timely way. Women are also asked to report on their own and their partner's employment status at the time of the survey interview, and this may have changed since the time of their most recent pregnancy. The DHS does not include questions that are directly related to the barriers to seeking ANC or accessing ANC facilities. However, we used the question about who makes decisions about the woman's health care as a measure of one potential barrier to access of services. Our findings do not reflect other potential barriers such as distance to a facility or associated financial costs. Another limitation is that the data we were able to obtain on policies and programs in each country varied greatly, and because most of our key informants volunteered their time, it was not always possible to confirm all details or to seek additional information and clarification within the time frame of this study.

Nevertheless, this analysis has several strengths. We examine ANC utilization from a new perspective, focusing specifically on information missed by global tracking of only two indicators. The study brings together several types of analysis-descriptive, equity, and inferential analysis-to generate new and detailed results of specific characteristics of women and their households that are associated with ANC utilization patterns in seven diverse countries.

\section{CONCLUSION}

The results of this study indicate that reporting the globally measured ANC indicators, ANC 1+ and ANC 4+, is useful to provide an overall idea of the proportions of ANC utilization in countries. However, descriptive and multivariable analyses generated a much better understanding of each country's unique pattern of ANC utilization, as well as the characteristics of women not currently receiving adequate care. The presence of variations across countries suggests the need for specific in-country assessments, national panels, or advisory groups to look more closely at national data, commission specific studies and perhaps try different models of ANC to find ways to achieve universal ANC coverage.

A number of predominant aspects of ANC utilization patterns emerged across the seven Countdown countries. Our results highlight the need to focus on evidence-based content interventions offered to women during their ANC visits. Further quantitative assessments of the frequency and timeliness of content interventions by different types of providers and in different settings are needed to ensure proper administration of the WHO-recommended interventions. Moreover, qualitative studies looking into the barriers of ANC use and women's perceptions of ANC services in each country are essential. There is a growing body of literature that focuses on women's perceptions of pregnancy and quality of ANC services and how important this aspect is on ANC uptake. The current DHS protocol asks about barriers to seeking health care in general; it may provide important insights to include a question specifically about the numerous barriers that may affect women's initiation of ANC and completion of the four recommended visits.

Inequality in ANC utilization patterns among women of different wealth statuses, educational backgrounds and places of residence need to be considered at the policymaking level across most of the countries we studied. These dimensions of inequality were strong predictors of ANC utilization and higher frequency of visits, except for place of residence. The influence of place of residence on ANC utilization in Bangladesh and Senegal suggests the need to assess the health care services offered in rural areas. And the lack of significance of this factor in the five other countries suggests that there are variations within each place of residence that need to be identified and used to provide effective interventions. While we found that policies and guidelines related to ANC as well as 'Safe Motherhood' strategies were incorporated into the national policies, 
across the seven countries, yet, there is a need to ensure evaluation and proper implementation of these policies and strategies. Peru is an example of successful implementation of political and structural reform, which took place in the 1990s, and led to the enhancement of health systems and infrastructure, reduction in poverty, and the introduction of insurance schemes, one of which is for pregnant mothers, among other groups [50].

With the end of the MDG era, few countries have achieved the MDG5 goal of reducing maternal mortality by three quarters, and most have a long way to go before achieving universal access to reproductive health services [13]. Most maternal deaths are preventable, and the causes of these deaths are known $[2,47,51]$. By increasing attention and investment to providing quality maternity, antenatal, and post-partum care, life-saving interventions may be administered properly and in a timely manner by skilled health providers to help improve maternal and neonatal health and their survival [2]. In the post-2015 agenda, as the Sustainable Development Goals and their measurable indicators are being set, it is essential to include targets for ending preventable maternal deaths and to ensure that the momentum focusing on maternal and reproductive healthwith ANC as a vital component-continues [51].

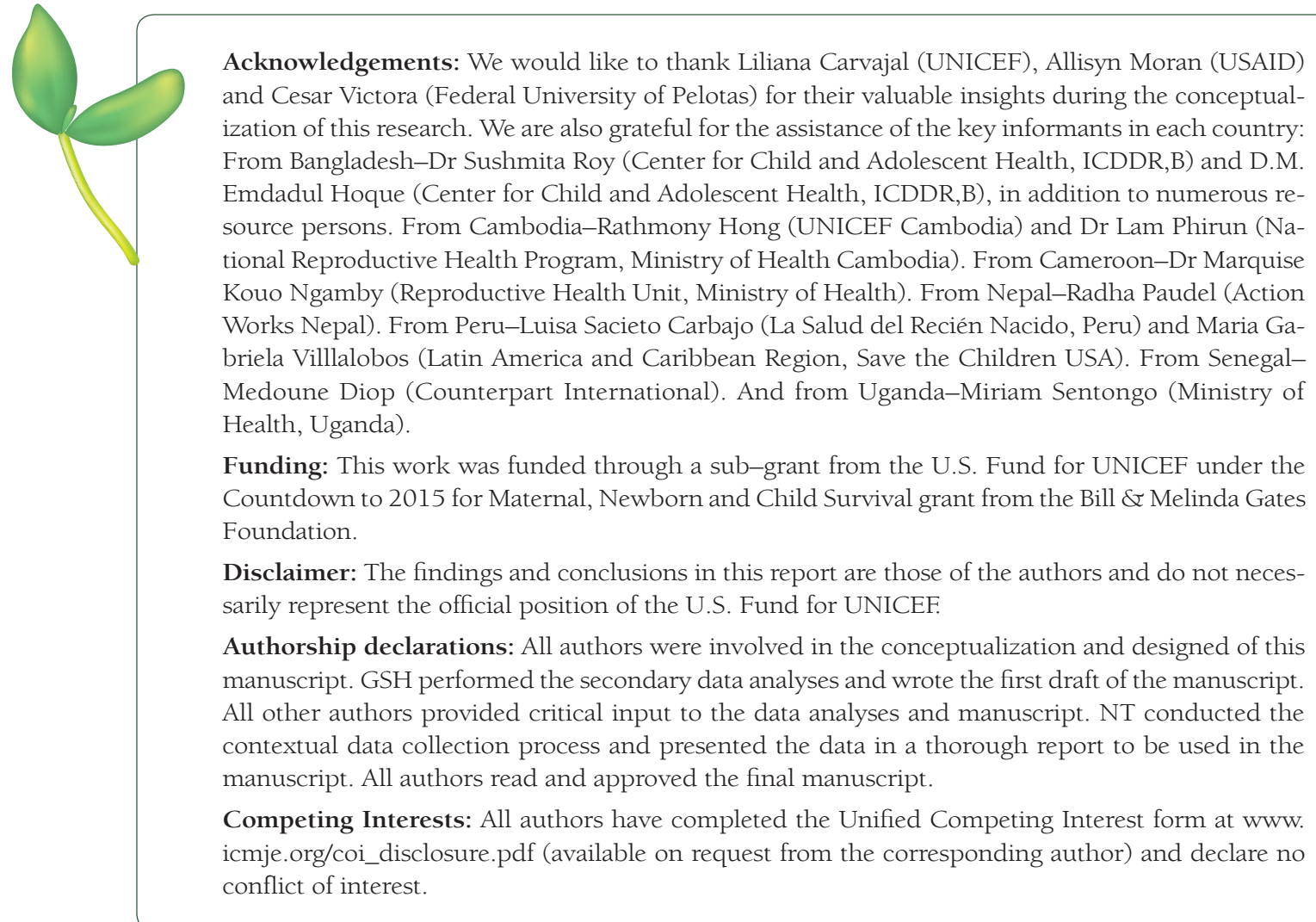

1 United Nations. Framework of actions for the follow-up to the Programme of Action of the International Conference on Population and Development Beyond 2014. United Nations, 2014.

2 United States Agency for International Development. Ending preventable maternal mortality: USAID maternal health vision for action - Evidence for strategic approaches. Washington DC: USAID, 2015.

3 Lincetto O, Mothebesoane-Anoh S, Gomez P, Munjanja S, Munjanja S. Chapter 2: Antenatal care In: Lawn J, Kerber K, editors. Opportunities for Africa's Newborns: practical data, policy and programmatic support for newborn care in Africa. Geneva: World Health Organization; 2006. p. 51-62.

4 World Health Organization. Standards for maternal and neonatal care. Geneva: World Health Organization; 2007.

5 World Health Organization. Pregnancy, childbirth, postpartum and newborn care: a guide for essential practice. Report No.: 3rd edition. Geneva: WHO, 2015. 1-184 p.

6 Dowswell T, Carroli G, Duley L, Gates S, Gülmezoglu AM, Khan-Neelofur D, Piaggio GGP. Alternative versus standard packages of antenatal care for low-risk pregnancy. Cochrane Database Syst Rev. 2010;(10):CD000934. Medline:20927721

7 World Health Organization. WHO Antenatal care randomized trial: manual for the implementation of the new model. Geneva: World Health Organization, 2002. 
8 Villar J, Carroli G, Khan-Neelofur D, Piaggio G, Gülmezoglu M. Patterns for routine antenatal care for low-risk pregnancies care. Cochrane Database Syst Rev. 2001;(4):CD000934. Medline:11687086

9 World Health Organization. WHO statement on antenatal care. Geneva: WHO, 2011.

10 Vogel JP, Abu Habib N, Souza JP, Gulmezoglu AM, Dowswell T, Carroli G, et al. Antenatal care packages with reduced visits and a perinatal mortality: A secondary analysis of the WHO antenatal care trial. Reprod Health. 2013;10:19-26. Medline:23577700 doi:10.1186/1742-4755-10-19

11 Kearns A, Millar K. Continuum of care series: Providing for mom and baby through antenatal and postnatal care. Maternal Health Task Force Blog 2014 Aug 1. Available: http://www.mhtf.org/2014/08/01/call-for-posts-continuum-of-care-series-providing-for-mom-and-baby-through-antenatal-and-postnatal-care/. Accessed: 1 February 2015.

12 United Nations. Indicators for monitoring the Millennium Development Goals: definitions, rational, concepts and sources 2012. Available: http://mdgs.un.org/unsd/mi/wiki/MainPage.ashx. Accessed: 9 April 2015.

13 World Health Organization. Countdown to 2015. Fulfilling the health agenda for women and children: the 2014 report. Geneva: WHO, 2014.

14 Magadi MA, Madise NJ, Rodrigues RN. Frequency of timing of antenatal care in Kenya: Explaining the variations between women of different communities. Soc Sci Med. 2000;51:551-61. Medline:10868670 doi:10.1016/ S0277-9536(99)00495-5

15 Sepehri A, Sarma S, Simpson W, Moshiri S. How important are individual, household and commune characteristics in explaining utilization of maternal health services in Vietnam? Soc Sci Med. 2008;67:1009-17. Medline:18635302 doi:10.1016/j.socscimed.2008.06.005

16 Alexandre PK, Saint-Jean G, Crandell L, Fevrin E. Prenatal care utilization in rural areas and urban areas of Haiti. Rev Panam Salud Publica. 2005;18:84-92. Medline:16156958 doi:10.1590/S1020-49892005000700002

17 Beeckman K, Louchx F, Putman K. Determinants of the number of antenatal visits in a metropolitan region. BMC Public Health. 2010;10:527-36. Medline:20809951 doi:10.1186/1471-2458-10-527

18 Gayawan E. A poisson regression model to examine spatial patterns in antenatal care utilization in Nigeria. Popul Space Place. 2014;20:485-97. doi:10.1002/psp.1775

19 Guliani H, Sepehri A, Serieux J. Determinants of prenatal care use: evidence from 32 low-income countries across Asia, sub-Saharan Africa and Latin America. Health Policy Plan. 2014;29:589-602. Medline:23894068 doi:10.1093/heapol/czt045

20 Kishowar Hossain AH. Utilization of antenatal care services in Bangladesh: an analysis of levels, patterns, and trends from 1993 to 2007. Asia Pac J Public Health. 2010;22:395-406. Medline:20498123 doi:10.1177/1010539510366177

21 Shrestha G. Factors related to utilization of antenatal care in Nepal: a generalized linear approach. Journal of Kathmandu Medical College. 2013;2:69-74.

22 Celik Y, Hotchkiss DR. The socio-economic determinants of maternal health care utilization in Turkey. Soc Sci Med. 2000;50:1797-806. Medline:10798333 doi:10.1016/50277-9536(99)00418-9

23 Magadi MA, Zulu EM, Brockerhoff M. The inequality of maternal health care in urban sub-Saharan Africa in the 1990s. Pop Stud (Camb). 2003;57:347-66. Medline:14602534 doi:10.1080/0032472032000137853

24 Mekonnen Y, Mekonnen A. Factors influencing the use of maternal healthcare services in Ethiopia. J Health Popul Nutr. 2003;21:374-82. Medline:15038593

25 Saxena D, Vangani R, Mavalankar DV, Thomsen S. Inequity in maternal health care service utilization in Gujarat: Analyses of district-level health survey data. Glob Health Action. 2013;6:1-9. Medline:23469890

26 Houweling TAJ, Ronsmans C, Campbell OMR, Kunst AE. Huge-poor-rich inequalities in maternity care: an international comparative study of maternity and child care in developing countries. Bull World Health Organ. 2007;85:745-54. Medline:18038055 doi:10.2471/BLT.06.038588

27 Simkhada B, van Teijlingen ER, Porter M, Simkhada P. Factors affecting the utilization of antenatal care in developing countries: systematic review of the literature. J Adv Nurs. 2008;61:244-60. Medline:18197860 doi:10.1111/j.1365-2648.2007.04532.x

28 Finlayson K, Downe S. Why do women not use antenatal services in low- and middle-income countries? A meta-synthesis of qualitative studies. PLoS Med. 2013;10:e1001373. Medline:23349622 doi:10.1371/journal. pmed. 1001373

29 USAID. The DHS Program: Demographic and Health Surveys. Maryland: ICF International. Available: http:// dhsprogram.com/. Accessed: 1 November 2012.

30 Andersen RM. Revisiting the behavioral model and access to medical care: Does it matter? J Health Soc Behav. 1995;36:1-10. Medline:7738325 doi:10.2307/2137284

31 Hodgins S, D'Agostino A. The quality-coverage gap in antenatal care: toward better measurement of effective coverage. Glob Health Sci Pract. 2014;2:173-81. Medline:25276575 doi:10.9745/GHSP-D-13-00176

32 Babitsch B, Gohl D, Lengerke TV. Re-visiting Anderson's behavioral model of health services use: a systematic review of studies from 1998-2011. Psychosoc Med. 2012;9:Doc11. Medline:23133505

33 Chakraborty N, Islam AM, Chowdhury RI, Bari W, Akhter HH. Determinants of the use of maternal health services in rural Bangladesh. Health Promot Int. 2003;18:327-37. Medline:14695364 doi:10.1093/heapro/dag414

34 Victora CG, Huttly SR, Fuchs SC, Olinto MT. The role of conceptual frameworks in epidemiological analysis: a hierarchical approach. Int J Epidemiol. 1997;26:224-7. Medline:9126524 doi:10.1093/ije/26.1.224 
35 Boerma JT, Bryce J, Kinfu Y, Axelson H, Victora CG. Mind the gap: equity and trends in coverage of maternal, newborn, and child health services in 54 countdown countries. Lancet. 2008;371:1259-67. Medline:18406860 doi:10.1016/S0140-6736(08)60560-7

36 Mo HP. [Nepal]. National Medical Standard for Reproductive Health. Report No.: Volume III: Maternal and Newborn Care. Kathmandu: Family Health Division, Ministry of Health and Population, Government of Nepal, 2009.

37 Dahal RK. Utilization of antenatal care services in rural area of Nepal. Int J Collab Res Intern Med Public Health. 2013;5:120-31.

38 Mridha MK, Anwar I, Koblinski M. Public-sector maternal health programmes and services for rural Bangladesh. J Health Popul Nutr. 2009;27:124-38. Medline:19489411 doi:10.3329/jhpn.v27i2.3326

39 Powell-Jackson T, Macleod D, Benova L, Lynch C, Campbell O. The role of private sector in the provision of antenatal care: a study of demographic and health surveys from 64 low- and middle-income countries. Trop Med Int Health. 2015;20:230-9. Medline:25358532 doi:10.1111/tmi.12414

40 Huicho L, Segura E, Huayanay C, Nińo de Guzman J, Restrepo-Mendez MC, et al. Placing child health and nutrition at the centre of the antipoverty political agenda: the Peruvian experience, 2000-2013. Lancet Glob Health. 2015. submitted

41 Say L, Raine R. A systematic review of inequalities in the use of maternal health care in developing countries: examining the scale of the problem and the importance of context. Bull World Health Organ. 2007;85:812-9. Medline:18038064 doi:10.2471/BLT.06.035659

42 Mathews SA, Gubhaju B. Contextual influences on the use of antenatal care in Nepal. Report No.: DHS Geographic Studies 2. Calverton, Maryland: ORC Macro, 2004.

43 Government of Bangladesh. Bangladesh Maternal Mortality and Health care Survey (BMMS). Bangladesh: Government of Bangladesh, 2010.

44 Matsuoka S, Aiga H, Rasmey LC, Rathavy T, Okitsu A. Perceived barriers to utilization of maternal health services in rural Cambodia. Health Policy. 2010;95:255-63. Medline:20060193 doi:10.1016/j.healthpol.2009.12.011

45 Simkhada B, Porter MA, van Teijlingen ER. The role of mothers-in-law in antenatal care decision-making in Nepal: A qualitative study. BMC Pregnancy Childbirth. 2010;10:34. Medline:20594340 doi:10.1186/1471-2393$10-34$

46 Ndyomugyenyi R, Neema S, Magnussen P. The use of formal and informal services for antenatal care and malaria treatment in rural Uganda. Health Policy Plan. 1998;13:94-102. Medline:10178189 doi:10.1093/ heapol/13.1.94

47 The independent Expert Review Committee. Every woman, every child: a post-2015 vision: the third report of the independent Expert Review Group on Information and Accountability for Women's and Children's health. Geneva: WHO, 2014.

48 Downe S, Finayson K, Tuncalp O, Gulmezoglu AM. What matters to women: A systematic scoping review to identify the processes and outcomes of antenatal care provision that are important to healthy pregnant women. BJOG. 2015. doi:10.1111/1471-0528.13819. Epub ahead of print. Medline:26701735

49 Stanton CK, Rawlins B, Drake M, dos Anjos M, Cantor D, Chongo L, et al. Measuring coverage in MNCH: testing the validity of women's self-report of key maternal and newborn health interventions during the peripartum period in Mozambique. PLoS ONE. 2013;8:e60694. Medline:23667427 doi:10.1371/journal.pone.0060694

50 PAHO/WHO, Partnership for Maternal, Newborn \& Child Health, World Bank and Alliance for Health Policy and Systems Research. Success factors for women's and children's health: Peru. Geneva: World Health Organization; 2015.

51 Requejo JH, Bhutta ZA. The post-2015 agenda: staying the course in maternal and child survival. Arch Dis Child. 2015;100 Suppl 1:S76-81. Medline:25613979 doi:10.1136/archdischild-2013-305737 